\title{
Effects of Constant and Diel Cyclic Temperatures on The Liver and Intestinal Phospholipid Fatty Acid Composition in Rainbow Trout Oncorhynchus Mykiss During Seawater Acclimation
}

Jian Ge

Ocean University of China

Yangen Zhou ( $\nabla$ zhouyg@ouc.edu.cn )

Ocean University of China

Ming Huang

Ocean University of China

Qinfeng Gao

Ocean University of China

Yunwei Dong

Ocean University of China

Shuanglin Dong

Ocean University of China

\section{Research Article}

Keywords: constant temperature, diel cyclic temperature, phospholipid fatty acid composition, rainbow trout, seawater acclimation

Posted Date: February 16th, 2021

DOI: https://doi.org/10.21203/rs.3.rs-199139/v1

License: (a) (i) This work is licensed under a Creative Commons Attribution 4.0 International License. Read Full License 


\section{Abstract}

Background: Rainbow trout is an important economic fish in aquaculture and a model species in environmental physiology. Despite of earlier research on the seawater adaptability of rainbow trout at different temperature regimes, the influence on liver and intestine in this species is still unknown. Two trials were conducted to investigate the effects of constant and diel cyclic temperatures on phospholipid fatty acid (PLFA) composition in the liver and intestine of rainbow trout during seawater acclimation.

Results: At the end of the growth trial 1, fish at 9 and $12.5^{\circ} \mathrm{C}$ showed significantly higher ratios of unsaturated to saturated (U/S) and unsaturation index (UI) than those at $16^{\circ} \mathrm{C}$ in liver and intestine phospholipids. After day 1 of seawater acclimation, the $\mathrm{U} / \mathrm{S}, \mathrm{UI}$, and average chain length (ACL) of liver and intestine phospholipids in fish at $16^{\circ} \mathrm{C}$ significantly increased. Two weeks after seawater acclimation, liver and intestinal PLFA composition adapted to salinity change. In trial 2 , significantly higher $\mathrm{U} / \mathrm{S}$, UI, and $\mathrm{ACL}$ were found in intestinal phospholipids at $13 \pm 2^{\circ} \mathrm{C}$. On the first day after seawater acclimation, $\mathrm{UI}$ and $\mathrm{ACL}$ in liver phospholipids significantly increased in $13^{\circ} \mathrm{C}$, while fish in $13 \pm 2^{\circ} \mathrm{C}$ showed significantly decreased U/S, UI, and ACL in the intestine. At the end of the growth trial 2, liver PLFA compositions were stable, whereas intestinal PLFA in 13 and $13 \pm 1^{\circ} \mathrm{C}$ showed significantly decreased U/S, UI, and ACL. A two-way analysis of variance and principal component analysis revealed significant effects of different constant temperatures, seawater acclimation, and their interaction on the liver and intestinal phospholipids, a significant effect of diel cyclic temperature on intestinal phospholipids, and the effects of seawater acclimation and its interaction with diel cyclic temperature on liver phospholipids.

Conclusion: Temperatures of 9 and $12.5^{\circ} \mathrm{C}$ could elevate membrane fluidity and thickness in the liver and intestine of rainbow trout in freshwater, whereas no significant effects were found with diel temperature variations. After seawater acclimation, constant and diel cyclic temperatures significantly influenced the liver and intestine's membrane fluidity and thickness. Compared with constant temperature, diel temperature variation $\left(13 \pm 2^{\circ} \mathrm{C}\right)$ can enhance the adaptability of rainbow trout during seawater acclimation.

\section{Background}

Salmonids are one of the most important economically farmed species in the world. The global production of Atlantic salmon (Salmo salar) in 2018 exceeded 2.4 million tons, while that of rainbow trout (Oncorhynchus mykiss) reached 0.8 million tons [1]. The surge in demand for salmonids in China is mainly driven by consumers' preference for its tasty flesh and abundance of essential amino acids and polyunsaturated fatty acids (PLFAs) [2]. The discovery of the Yellow Sea Cold Water Mass opened up the possibility of offshore salmon mariculture $[3,4]$ and one of the pivotal stages of this project is the 'mountain-sea relay' mode, in which salmon are hatched and bred until the juvenile stage in freshwater in mountainous areas, transferred to seawater, and fattened to commercial size. Previous research has reported that the seawater tolerance of salmonids can be influenced by life stage [5], photoperiod [6], salinity stimulation [7], nutritional status [8,9] and temperature change $[10,11]$.

During adaptation to environmental changes (e.g. temperature and salinity), organisms alter the physical properties of the membrane, including fluidity, thickness, permeability, and viscosity, by restructuring the phospholipid fatty acid (PLFA) composition [12,13]. These changes will significantly influence the biological function of the membrane [14]. Biological membranes are susceptible to changes in temperature and salinity. When the temperature decreases, fish will increase the unsaturation degree to maintain sufficient fluidity, and vice versa $[15,16]$. When salinity increases, some fish increase membrane fluidity by elevating the proportion of unsaturated fatty acids [17]. 
Rainbow trout is a cold-water fish and can tolerate relatively high fluctuations in temperature and salinity. Environmental change induces adaptive alterations in fish tissues, and the restructuring of PLFA composition is an important step in regulating membrane function [18]. For instance, a decrease in temperature can increase membrane fluidity by increasing the degree of unsaturation in fish tissues, which has been demonstrated in alewives (Alosa pseudoharengus) [19], yellow perch (Perca flavescens) [20], steelhead trout (O. mykiss), and Atlantic salmon [15]. Similarly, fish living in seawater will also have a higher proportion of unsaturated fatty acids in tissue phospholipids, which can be used to maintain membrane function [21, 22].

To date, studies from our laboratory demonstrated that temperature could significantly influence the PLFA composition in salmonids $[15,16]$. Our data from Ge et al. [11] reported that temperatures of 12.5 and $13 \pm 2{ }^{\circ} \mathrm{C}$ are preferable for rainbow trout during seawater acclimation. However, the effects of seawater acclimation at different temperature regimes on liver and intestinal phospholipids in rainbow trout remain unknown. Thus, this study aimed to acclimate rainbow trout at different temperature regimes and analyse PLFA composition changes and seawater tolerance.

\section{Methods}

\section{Animals}

Rainbow trout were purchased from Wanzefeng Fishery Company (Rizhao, China). Fish were reared in aquariums and acclimated to an experimental environment where the water temperature was maintained at optimal levels (16.0 \pm 0.5 ${ }^{\circ} \mathrm{C}$ ) by a semi-recirculating system equipped with refrigeration and aeration facilities. Throughout the experiment, rainbow trout were fed to satiation with commercial dry feed by hand (Qihao Biotechnology Company, Qingdao, China) twice daily (0800 and $1800 \mathrm{hrs}$ ). All fish stocking and experimental procedures were performed in accordance with the ethical approval of the Ocean University of China and National Experimental Management Regulations in China and were approved by the Animal Experimentation Committee of the Ocean University of China (Reference Number, 2018-12). All animal studies were carried out in accordance with the ARRIVE guidelines [45]. The fatty acid composition of the feed is shown in Additional file 1.

\section{Experimental design}

In trial 1, rainbow trout with a similar initial weight $(94.73 \pm 9.70 \mathrm{~g})$ were randomly assigned to nine tanks $(186 \mathrm{~L} ; 0.58$ $\mathrm{m}$ height $\times 0.65 \mathrm{~m}$ diameter), where the water temperature was maintained at $16 \pm 0.5^{\circ} \mathrm{C}$ by a recirculating system equipped with refrigeration facilities. Each treatment had three replications with ten fish per tank $(n=3$; biomass, 5.09 $\left.\mathrm{kg} \cdot \mathrm{m}^{3-1}\right)$. The temperature of dechlorinated freshwater was controlled by a temperature control system (ZKH-WK 2000, Zhongkehai, Qingdao, China), fluctuating within $0.5^{\circ} \mathrm{C}$. The temperature regimes were as follows: water temperature was gradually adjusted from $16^{\circ} \mathrm{C}(\mathrm{T} 16)$ to $12.5^{\circ} \mathrm{C}(\mathrm{T} 12.5)$ and $9{ }^{\circ} \mathrm{C}$ (T9) at a rate of $2{ }^{\circ} \mathrm{C}$ per $12 \mathrm{~h}$, and then kept constant for the rest of the experiment. The fish were subjected to temperature acclimation in freshwater for 28 days. Immediately after acclimation, the salinity of all tanks was increased to $14 \mathrm{ppt}$ from 0 ppt by mixing with seawater (salinity $30 \pm 1 \mathrm{ppt}$ ) within $60 \mathrm{~min}$, and then further increased from $14 \mathrm{ppt}$ to $30 \mathrm{ppt}$ at a rate of 2 ppt day-1, according to the method described by Xiong et al. (2020). Filtered and dechlorinated seawater was drawn from the coastal waters of the Yellow Sea. The water at the desired salinity was prepared in advance and pumped into the tanks. After that, fish were stocked for 14 days. 
In trial 2, juvenile rainbow trout with a similar initial weight (62.28 $\pm 0.41 \mathrm{~g})$ were randomly allocated to 12 tanks (186 $\mathrm{L} ; 0.58 \mathrm{~m}$ height $\times 0.65 \mathrm{~m}$ diameter). Each treatment was replicated four times, with ten fish per tank. The temperature of dechlorinated freshwater was controlled by an Al temperature controller (Al-526P, Yudian Tech, Xiamen, China) with an accuracy of $0.05{ }^{\circ} \mathrm{C}$. The temperature regimes were conducted as follows: water temperature was gradually adjusted from 16.0 to $13.0^{\circ} \mathrm{C}$ in $12 \mathrm{~h}$, after which the fish were subjected to three experimental thermal regimes. These regimes are referred to as CT, VT2, and VT4. CT mimics a laboratory scenario where the temperature is constant at $13.0^{\circ} \mathrm{C}$ while VT2 and VT4 mimic a natural scenario where the temperature oscillates daily by the same magnitude. In VT2, the fluctuation in temperature is $2.0^{\circ} \mathrm{C}$, changing between 12.0 and $14.0^{\circ} \mathrm{C}$, in a sinusoid manner. VT4 represents a scenario with a larger daily magnitude of fluctuation between 11.0 and $15.0^{\circ} \mathrm{C}$, also in a sinusoid manner. The fish were subjected to temperature acclimation in freshwater for six weeks. Immediately after acclimation, the salinity of all tanks was increased to $15 \mathrm{ppt}$ from 0 ppt by mixing with seawater (salinity $30 \pm 1 \mathrm{ppt}$ ), and then further increased to $30 \mathrm{ppt}$ from $15 \mathrm{ppt}$ at a rate of $3 \mathrm{ppt}$ per day, according to the method described by Huang et al. [8]. The water at the desired salinity was prepared in advance and pumped into the tanks. After that, fish were stocked for three weeks.

Approximately $100 \%$ of the water in each tank was manually changed daily. The water was prepared to be at the desired temperature before pumping into the tanks. Water quality [dissolved oxygen (DO), $\mathrm{pH}$, nitrate, and ammonia] was monitored thrice weekly using a YSI Pro Plus Multiparameter (YSI Incorporated, Yellow Springs, Ohio, USA), and salinity was measured daily using a seawater refractometer. DO content was $>8.7 \mathrm{mg} \bullet \mathrm{L}^{-1}$, photoperiod was $12: 12-\mathrm{h}$ (light/dark), $\mathrm{pH}$ was $7.2 \pm 0.7$, ammonia level was $0.04 \pm 0.02 \mathrm{mg} \cdot \mathrm{L}^{-1}$, and nitrate was $1.17 \pm 0.33 \mathrm{mg} \cdot \mathrm{L}^{-1}$.

\section{Sampling procedures}

Fish were fasted for $24 \mathrm{~h}$ prior to sampling and euthanised using MS-222 (60 mg•L ${ }^{-1}$; Sigma-Aldrich, St. Louis, MO, USA). Tissue samples were collected from each treatment on the last day in freshwater (FW-28 in trial 1 and FW-42 in trial 2), and on the first (SW-1) and final (SW-14 in trial 1 and SW-21 in trial 2) days in seawater, immediately frozen in liquid nitrogen, and stored at $-80^{\circ} \mathrm{C}$ after dissection.

\section{Lipid extraction and PLFA analysis}

Lipid extraction and PLFA analysis were performed according to Ge et al. [11]. Briefly, liver and intestine (0.1 g) were homogenised in chloroform/methanol $(2: 1, \mathrm{v} / \mathrm{v})$. The crude extract was precipitated proteins and separated into two phases. The lower phase was then dried to a constant weight under nitrogen flow to obtain lipids. Solid lipids were diluted with $20 \mu \mathrm{L}$ petroleum ether $\left(60-90^{\circ} \mathrm{C}\right)$ and spotted on one-dimensional thin-layer hybrid silica gel plates (100 $\times 100 \mathrm{~mm}$, Haiyang Company, Qingdao, China) to obtain phospholipids. The phospholipids were visualised by iodine vapour and esterified at $90^{\circ} \mathrm{C}$ for 90 min to obtain fatty acid methyl esters (FAMEs) [16].

The FAMEs were injected into a gas chromatograph (GC-2010 plus; Shimadzu, Kyoto, Japan) equipped with an RTXWAX fused silica capillary column (30 $\mathrm{m} \times 0.25 \mathrm{~mm} \times 0.25 \mu \mathrm{m}$, Phenomenex, Torrance, CA, USA) and a flame ionisation detector (FID; GC-2010, Shimadzu, Kyoto, Japan). The temperature setting of the column oven started from an initial temperature of $80^{\circ} \mathrm{C}$ for $1 \mathrm{~min}$, then serially increased as follows: $180^{\circ} \mathrm{C}$ at a rate of $8{ }^{\circ} \mathrm{C} \mathrm{min}{ }^{-1}$ for 5 min, $220^{\circ} \mathrm{C}$ at a rate of $4{ }^{\circ} \mathrm{C} \mathrm{min}-1,224^{\circ} \mathrm{C}$ at a rate of $0.5^{\circ} \mathrm{C} \mathrm{min}{ }^{-1}, 280^{\circ} \mathrm{C}$ at a rate of $4{ }^{\circ} \mathrm{C} \mathrm{min}-1$ for 10 min. FAMEs were classified and quantified by comparing retention times and areas of the peak using the 37-FAME Mix standards (Supelco, Bellefonte, Pennsylvania, USA). 


\section{Biometric indices}

The indices of PLFA composition (FA-related indices) were calculated according to the following formulae, as previously used by Wallaert et al. [46], Snyder et al. [47] and Cornelius et al. [48]:

$$
\begin{gathered}
\mathrm{UI}=\sum(\% \text { monoene }+2 \times \% \text { dienes }+3 \times \% \text { trienes ... }) / 100 \\
\mathrm{U} / \mathrm{S}=\sum \% U F A / \sum \% S F A \\
\mathrm{ACL}=\sum(14 \times \% 14 C+16 \times \% 16 C+17 \times \% 17 C \ldots) / 100
\end{gathered}
$$

Ul: unsaturation index; monoene, dienes, trienes: the numbers of double bonds that fatty acids contain; \%: weight percentage; U/S: the ratio of unsaturated fatty acids to saturated fatty acids; UFA: unsaturated fatty acids; SFA: saturated fatty acids; ACL: average chain length of phospholipid; n-3 PUFA: omega-3 series polyunsaturated fatty acids; $n-6$ PUFA: omega- 6 series polyunsaturated fatty acids; $n 3 / n 6$ : the ratio of $n-3$ PUFA to $n-6$ PUFA.

\section{Statistical analyses}

Statistical analyses were performed using SAS 9.4 (SAS Institute, Cary, NC, USA). All data sets were tested for normality and homogeneity of variances using Levene's test and then tested using one- and two-way analysis of variance (ANOVA) to determine if significance existed among different treatments, followed by the StudentNewman-Keuls multiple range test. Principal component analysis (PCA) and data visualisation were performed using GraphPad Prism 9.0.0 (GraphPad Software Inc., San Diego, CA, USA). All data are expressed as the mean \pm SD. A $P$ value less than 0.05 was regarded as statistically significant.

\section{Results}

\section{Effects of constant temperature on liver phospholipid fatty acid composition (PLFA) during seawater acclimation}

In trial 1, after rearing in freshwater for four weeks (FW-28), the liver PLFA composition of rainbow trout was significantly altered by different constant temperatures (Table 1). In treatments of 9 (T9) and $12.5^{\circ} \mathrm{C}$ (T12.5), the proportions of 16:0 and 18:0 significantly lowered ratio of saturated fatty acid (SFA) in liver phospholipids. The proportion of monounsaturated fatty acid (MUFA) in liver phospholipids was significantly lower in treatment of $16^{\circ} \mathrm{C}$ (T16) than in T12.5, but significantly higher than in treatment $T 9$, mainly caused by $18: 1 \mathrm{n} 9$. The proportion of polyunsaturated fatty acids (PUFAs) in the liver phospholipids of rainbow trout was negatively correlated with temperature; the proportion of PUFAs in T9 was the highest, followed by T12.5 and T16. The ratio of unsaturated to saturated fatty acid (U/S) in T9 and T12.5 was significantly higher than in T16, while the unsaturation index (UI) in T9 was significantly higher than in T16. The ratio of n-3 PUFA to n-6 PUFA (n3/n6) in T9 and T12.5 was significantly higher than in T16 (Fig. 1A-D). In addition, the average chain length (ACL) of fatty acid in T9 was significantly higher than in the other groups. 
At the first day after seawater acclimation (SW-1), the liver PLFA composition in rainbow trout was significantly altered (Table 1). The proportion of SFA in liver phospholipids significantly decreased in T16, whereas those in T9 and T12.5 increased, significantly higher than in T16. The total MUFA in T12.5 significantly decreased, while those in other groups remained unchanged. The proportion of PUFAs in T9 increased to 55.75\%, close to the level in T12.5. Fig. 1 shows a significantly low U/S in T9 and a significantly high ACL in T12.5, but no significant difference in UI among groups.

Two weeks after seawater acclimation, the total SFA in T9 significantly decreased and was significantly lower than in T12.5 (Table 1). The total MUFA in T16 considerably increased and was significantly higher than in other groups. Consequently, the UI in T9 and T16 increased and was significantly higher than in T12.5. These changes resulted in significantly higher UI, U/S, and ACL in T9 (Fig. 1A-D).

\section{Effects of constant temperature on intestinal PLFA composition during seawater acclimation}

In trial 1, after rearing in freshwater for four weeks, the intestinal PLFA composition in rainbow trout was altered significantly (Table 2). The total SFA in T9 and T12.5 decreased significantly, while the total PUFAs in T9 and T12.5 were significantly higher in T16. The total MUFA in T12.5 significantly decreased and was significantly lower than in T16. These changes resulted in significantly higher U/S, UI, and ACL in T9 and T12.5 than in T16 (Fig. 1E-H). The $\mathrm{n} 3 / \mathrm{n} 6$ ratio was positively associated with temperature.

On the first day after seawater acclimation, the total SFA in T16 significantly decreased. The total MUFA in T9 and T16 significantly decreased whereas that in T12.5 increased and was significantly higher than in other groups. The total PUFA in T9 and T16 significantly increased, while that in T12.5 was relatively steady. Consequently, significant increases in $\mathrm{n} 3 / \mathrm{n} 6, \mathrm{U} / \mathrm{S}, \mathrm{UI}$, and $\mathrm{ACL}$ were recorded in T16.

Two weeks after seawater acclimation (SW-14), the total SFA in T16 decreased while the other groups showed no significant difference (Table 2). The total MUFA in all groups decreased significantly. Accordingly, the total PUFA in all groups increased but showed no difference. Thus, the UI in T9 was significantly higher than in other groups, whereas no difference was found in UI and ACL in liver phospholipids in rainbow trout (Fig. 1E-H).

\section{Effects of diel cyclic temperature on liver PLFA composition during seawater acclimation}

In trial 2, at the final day of growth trial (FW-42), the proportion of $16: 0$ in the treatment of $13^{\circ} \mathrm{C}(\mathrm{CT})$ was significantly decreased while that of $20: 4 \mathrm{n} 6$ in the treatment of $13 \pm 1{ }^{\circ} \mathrm{C}(\mathrm{VT} 2)$ and $13 \pm 2{ }^{\circ} \mathrm{C}$ (VT4) remained steady (Table 3 ). However, no significant change was found in total SFA, MUFA, and PUFA among the groups. Therefore, there was no difference among groups in terms of $\mathrm{U} / \mathrm{S}, \mathrm{UI}$, and n3/n6, except for a significantly higher ACL in VT2 (Fig. 2A-D).

At SW-1, the total SFA of liver phospholipids in CT and VT2 increased significantly, while VT4 showed no significant change (Table 3). An overall decrease in total MUFA was detected in all groups, and the CT group showed significantly lower total MUFA than the VT2 and VT4 groups. Furthermore, the proportion of 22:6n3 was significantly lower in VT2 and VT4 than in CT, while total PUFA showed no difference among groups. These changes resulted in significantly higher Ul in CT than in VT2. ACL and n3/n6 were significantly higher in CT than in VT2 and VT4 (Fig. 2A-D). 
In trial 2, two weeks after seawater acclimation, the total SFA in all groups increased significantly and showed no difference in liver phospholipids of rainbow trout (Table 3). The total MUFA in CT increased to 7.88\%, while in VT2 and VT4 it was comparatively steady. The total PUFA in VT2 and VT4 decreased significantly and showed no difference among groups. The PLFA-related parameters showed no significant difference among groups.

\section{Effects of diel cyclic temperature on intestinal PLFA composition during seawater acclimation}

In trial 2, after six weeks in freshwater, the intestinal PLFA composition of rainbow trout was significantly influenced by diel cyclic temperature (Table 4). The total SFA in VT4 was significantly lower than in CT and VT2. A significantly high proportion of 22:6n3 was recorded in VT4, resulting in a significantly high total PUFA in VT4. Correspondingly, the $\mathrm{U} / \mathrm{S}, \mathrm{UI}, \mathrm{n3} / \mathrm{n6}$, and ACL in VT4 were significantly higher than in CT and VT2 (Fig. 2E-H).

At SW-1, significant decreases in the proportions of 16:0 and 18:0 were detected in CT in the intestinal phospholipids of rainbow trout (Table 4). The total MUFA in VT4 significantly increased and was significantly higher than that in CT and VT2. The proportion of 22:6n3 in CT and VT2 increased significantly, whereas that in VT4 decreased. Consequently, the total PUFA in CT was significantly higher than in VT2 and VT4 (Fig. 2E-H). These changes caused significantly higher U/S in CT than VT2 and VT4, whereas the UI and ACL in VT4 were significantly lower than in the other groups.

At SW-21, the intestinal phospholipids contained significantly lower proportions of 18:1n9 and 18:2n6 in CT than in VT2 and VT4, whereas the proportion of 22:6n3 in CT was significantly higher than in VT2 and VT4 (Table 4). However, no significant difference was observed in the total SFA, MUFA, and PUFA among the groups. The UI, n3/n6, and ACL in CT were significantly higher than in VT2 and VT4 (Fig. 2E-H).

\section{A two-way analysis of variance}

In trial 1, the two-way analysis of variance (ANOVA) indicated that both the liver and intestine in rainbow trout were significantly influenced by constant temperature, seawater acclimation, and their interaction (see Additional file 3 ). In trial 2, the diel cyclic temperature had no significant effect on liver PLFA composition, whereas seawater acclimation significantly influenced the total SFA, n3/n6, U/S, UI, and ACL in the liver PLFA composition. Therefore, the total SFA, $\mathrm{n} 3 / \mathrm{n} 6, \mathrm{U} / \mathrm{S}$, UI, and ACL were significantly influenced by the interaction of diel cyclic temperature and seawater acclimation. In the intestinal phospholipids, all selected parameters were significantly affected by diel cyclic temperature, seawater acclimation, and their combination, except total MUFA, which was free of the effect of temperature.

\section{Principal component analysis}

In the present study, principle component analysis (PCA) was performed to reveal the tissue differences in rainbow trout at different temperature regimes and seawater acclimation stages. Based on the results of the two-way ANOVA, 16 variables $(14: 0,16: 0,18: 0,16: 1,18: 1 n 9,24: 1,18: 2 n 6,20: 2 n 6,20: 3 n 3,20: 4 n 6,20: 5 n 3$, and 22:6n3, U/S, Ul, n3/n6, and $A C L)$ were selected for the liver of rainbow trout, while nine variables $(14: 0,18: 0,14: 1,16: 1,18: 1 n 9,18: 2 n 6$, $18: 3 n 3,20: 5 n 3,22: 6 n 3, U / S, U I, n 3 / n 6$, and ACL) were selected for the intestine. 
In trial 1, the first two principal components (PCs) with eigenvalues of 6.68 and 3.72 were found to explain $69.34 \%$ of the overall variability. The eigenvectors of $16: 1,18: 0,18: 1 n 9,18: 2 n 6,22: 6 n 3, U / S, U I, n 3 / n 6$, and ACL were more than 0.4 , indicating a strong effect on the PCs. The score plots distinguished the liver PLFA composition of rainbow trout at different constant temperatures and seawater acclimation stages (Fig. 3A). PCA analysis of the intestinal PLFA composition yielded two PCs with eigenvalues of 6.70 and 2.44 , explaining $76.06 \%$ of the dataset variance. The eigenvectors for 14:0, 14:1, 18:1n9, 18:3n3, 20:5n3, 22:6n3, U/S, UI, n3/n6, and ACL were greater than 0.4, resulting in the difference in intestinal PLFA composition of rainbow trout at different temperatures and seawater acclimation stages (Fig. 3B).

In trial 2, two of three PCs were selected for PCA on liver PLFA composition, and their eigenvalues were 5.69 and 3.54 and explained $65.88 \%$ of the total variability. The eigenvectors for $16: 1,16: 0,18: 2 n 6,18: 1 n 9,18: 0,20: 5 n 3,20: 3 n 3$, $\mathrm{n3/n6}$ and U/S exceeded 0.4. However, individuals of liver PLFAs only clustered at FW-42 and SW-21 instead of temperature regimes (Fig. 3C). Analysis of the intestinal PLFA composition produced two PCs with eigenvalues of 6.68 and 2.13 , explaining $73.45 \%$ of the accumulated variability. Eigenvectors of more than 0.4 included 16:0, 18:2n6, $18: 1 n 9,18: 0,20: 5 n 3,22: 6 n 3,24: 1, n 3 / n 6, U / S$, Ul, and ACL, contributing to the comparatively high differentiation in intestinal phospholipids of rainbow trout influenced by diel cyclic temperature and seawater acclimation (Fig. 3D).

\section{Discussion}

\section{Effects of constant temperature on the liver and intestinal PLFA composition in rainbow trout}

In order to adapt to different temperatures, fish can restructure the membrane phospholipids of tissues to maintain proper metabolism and physiological homeostasis [23-25]. In the constant temperature experiment, the two-way ANOVA indicated a significant effect of temperature on the liver and intestinal phospholipids in rainbow trout. The higher U/S and $\mathrm{UI}$ of the liver and intestinal phospholipids at 9 and $12.5^{\circ} \mathrm{C}$ indicated an increase in membrane fluidity. Similarly, when temperature decreased from 29 to $22^{\circ} \mathrm{C}$, the liver's membrane fluidity in the European seabass (Dicentrarchus labrax) significantly increased [26]. Leray et al. [27] reported that rainbow trout $(250 \mathrm{~g})$ living at $12{ }^{\circ} \mathrm{C}$ showed a significantly higher degree of unsaturation in the intestinal phospholipids than at $17^{\circ} \mathrm{C}$. Under lowtemperature conditions, regulation of the degree of unsaturation of phospholipids is essential for maintaining proper properties (fluidity, permeability, viscosity, and thickness) of cellular and organelle membranes [13, 28]. Contrarily, increased membrane fluidity of the liver and intestine helps increase the transmembrane efficiency and activity of membrane-bound enzymes, enhancing the ability to absorb and utilise nutrients [29]. This adaptation alleviates the adverse effects of low temperature, which limits the metabolic rate in fish $[23,25]$.

\section{Effects of constant temperature on the liver and intestinal PLFA composition in rainbow trout during seawater acclimation}

Notably, on the first day after seawater acclimation in trial 1, the $\mathrm{UI}$ of liver phospholipids in rainbow trout at different temperatures changed significantly and converged to a similar level; meanwhile individuals from all groups clustered at SW-1 in the PCA. The results indicated that the effect of seawater acclimation was more significant than temperature and that the tissue membranes of rainbow trout adjust for acclimation to seawater. Similarly, Borlongan et al. [30] found that milkfish (Chanos chanos Forsskal) contained a significantly higher degree of unsaturation of liver phospholipids in seawater than in freshwater, indicating that fish can respond to salinity change by altering membrane properties. In trial 1, two weeks after seawater acclimation, the UI and ACL in T12.5 and T16 changed 
significantly and reverted to levels before seawater acclimation, demonstrating that fish had basically completed the acclimation to salinity change. However, the liver PLFA composition of rainbow trout in T9 was significantly altered after seawater acclimation, but the fluidity remained unchanged, reflecting that temperature had more influence than salinity change.

In trial 1 , on the first day after seawater acclimation, the U/S, UI, n3/n6, and ACL of intestinal phospholipids significantly increased and reached a level close to T9 and T12.5, indicating a significant increase in fluidity, permeability, and thickness of the intestinal membrane. On the one hand, fish consume a large amount of energy for osmoregulation during seawater entry and can improve energy conversion efficiency by increasing membrane fluidity of the intestine to increase the efficiency of cross-membrane transportation and activities of membrane-bound enzymes [31, 32]. Brijs et al. [33] reported a dramatic increase in intestinal contractile activity in rainbow trout during seawater exposure, increasing the efficiency of absorptive processes. On the other hand, when fish are acclimated to seawater, ingested water and ions are absorbed by the intestine to maintain osmotic homeostasis [34]. Genz et al. [31] found a significant decrease in water, $\mathrm{Na}^{+}$, and $\mathrm{Cl}^{-}$in intestinal fluids after rainbow trout were acclimated to seawater, suggesting an enhanced absorption rate of the intestinal membrane. In the present study, the intestinal PLFA composition of rainbow trout showed no significant difference at SW-14, indicating that they had adapted to salinity change.

\section{Effects of diel cyclic temperature on the liver and intestinal PLFA composition in rainbow trout}

In trial 2, the liver phospholipids in rainbow trout showed no difference in U/S and UI. The two-way ANOVA and PCA analyses demonstrated that only seawater acclimation significantly influenced the intestinal PLFA composition. This because a) the liver of rainbow trout might have adapted to the diel cyclic changes in temperature after a 6-week stocking period under different temperature variations; b) the liver of rainbow trout contains large amounts of longchain PUFAs, suggesting better adaptability to temperature change due to higher membrane fluidity. Similarly, Eldridge et al. [35] subjected Atlantic salmon to periodic temperature for 30 days, and the results showed no significant difference in plasma cortisol, triglyceride, and histopathology.

It is noted that the $\mathrm{U} / \mathrm{S}, \mathrm{UI}$, and $\mathrm{ACL}$ in intestinal phospholipids of rainbow trout in VT4 were significantly higher than at constant temperature, indicating an increase in membrane fluidity of the intestine. PCA analysis results demonstrated that intestinal phospholipids in rainbow trout were more susceptible to temperature variations than liver phospholipids. Under diel cyclic temperature variation conditions, feed intake of fish will increase, and therefore the absorption efficiency of the intestinal membrane will be enhanced [35, 36]. Thomas et al. [37] reported that coho salmon (Oncorhynchus kisutch) under diel temperature cycles increased its energy reserves by enhancing energy utilisation efficiency.

\section{Effects of diel cyclic temperature on the liver and intestinal PLFA composition in rainbow trout during seawater acclimation}

In trial 2, after the first day of seawater acclimation, the liver phospholipids of rainbow trout significantly increased the $\mathrm{UI}$ and $\mathrm{ACL}$, consequently increasing the liver membrane's fluidity and thickness, indicating the liver's adaptation to seawater acclimation. Enhanced fluidity of the liver membrane is beneficial for the utilisation of nutrients and can increase the synthesis and secretion of antioxidants $[38,39]$. In trial 2, the liver PLFA composition of rainbow trout at 
VT4 was relatively stable, implying that diel cyclic temperatures could improve salinity tolerance to some extent. Similarly, after acclimation to periodic temperature variations for three days, the tolerance to acute heat stress in Atlantic salmon significantly improved [40]. Hokanson et al. [41] reported that rainbow trout subjected to daily temperature variations showed a higher growth rate and survival than those living at a constant temperature $\left(15^{\circ} \mathrm{C}\right)$. Our data showed that the liver PLFA compositions in all treatments were steady with no difference, suggesting that the adaptation to seawater had completed.

In trial 2, on the first day after seawater acclimation, PCA analysis indicated that clusters appeared at different stages of seawater acclimation, demonstrating that intestinal phospholipids were more susceptible to salinity change. Therefore, the U/S and UI of intestinal phospholipids significantly increased in CT but decreased in VT4, lowering the fluidity, permeability, and thickness of the intestinal membrane. These alterations represented adaptive changes in the intestine to counteract the salinity change in rainbow trout [42]. Decreased membrane fluidity can stimulate the activity of $\mathrm{Na}^{+}-\mathrm{K}^{+}$ATPase located on the intestinal membrane and consequently contribute to osmotic homeostasis in fish $[13,43,44]$. In trial 2 , the intestinal PLFA composition in all groups stabilised, implying that fish had adapted to the salinity change. Moreover, fish under diel temperature variation up to $4{ }^{\circ} \mathrm{C}$ showed a faster adaptation, proving that diel cyclic temperature can enhance the adaptability of rainbow trout to seawater acclimation.

\section{Conclusions}

In this study, different constant temperatures significantly influenced the liver and intestinal PLFA composition in rainbow trout. The fluidity and thickness of the liver and intestinal membrane significantly increased at 9 and $12.5^{\circ} \mathrm{C}$, respectively. During seawater acclimation, the liver and intestinal PLFA compositions were initially influenced by salinity change, and at $12.5^{\circ} \mathrm{C}$ more resilience was observed although fish at all selected temperatures showed stable PLFA composition after two weeks. At different diel cyclic temperatures, the intestinal membrane of rainbow trout at $13 \pm 2{ }^{\circ} \mathrm{C}$ had significantly increased fluidity, permeability, and thickness. During seawater acclimation, the liver's PLFA composition was more stable, while the PLFA composition of the intestine responded to salinity changes more rapidly. Therefore, different constant temperatures significantly influenced the liver and intestinal phospholipids in rainbow trout, while the appropriate diel cyclic temperature can improve the adaptability to seawater acclimation in the liver and intestine of rainbow trout.

\section{Declarations}

\section{Ethics approval and consent to participate}

Ethical approval for fish experiment was permitted by the Animal Experimentation Committee of the Ocean University of China (Reference Number, 2018-12). Fish husbandry and sample collection were in compliance with animal care protocols at the Ocean University of China and National Experimental Management Regulations in China.

\section{Consent for publication}

Not applicable.

\section{Availability of data and materials}

The data that support the findings of this study are available from the corresponding author upon reasonable request. 


\section{Competing interests}

All authors declare no conflict of interests.

\section{Funding}

This work was jointly supported by the National Key Research and Development Program of China (Project No. 2019YFD0901000), the National Natural Science Foundation of China (NSFC) (Nos. 31702364 and U1906206), and the Primary Research and Development Program of Shandong Province (Nos. 2018CXGC0101 and SD2019YY006).

\section{Authors' contributions}

JG carried out the entire experiment, analysed the data and drafted the manuscript with the guidance of YZ and SD. MH helped analyse samples. YZ was responsible for the integrity of the work as a whole. QG, and YD helped edit this manuscript.

\section{Acknowledgements}

We would like to express our gratitude to Chengyue Liu, Cui Han and Wenjuan Liu for their expertise and help in the phospholipid analysis. We also thank Xiaogang Yang, Rongxin Liu and Qianlong Deng for helping collect samples.

\section{References}

1. FAO (ed.). FAO Yearbook. Fishery and Aquaculture Statistics 2018. Rome, Italy; 2020. https://doi.org/10.4060/cb1213t

2. Xu H, Turchini GM, Francis DS, Liang M, Mock TS, Rombenso A et al. Are fish what they eat? A fatty acid's perspective. Prog Lipid Res. 2020; 80:101064. https://doi.org/10.1016/j.plipres.2020.101064

3. Han L, Guo Y, Dong S. Research on establishing a national offshore aquaculture experimental zone eased on the development of the Yellow Sea Cold Water Mass. Pac J. 2016; 24(5):79-85. https://doi.org/10.14015/j.cnki.10048049.2016.5.009

4. Dong S. Researching progresses and prospects in large salmonidae farming in Cold Water Mass of Yellow Sea. J Ocean Univ China. 2019; 49(03):1-6. https://doi.org/10.16441/j.cnki.hdxb.20180303

5. Bjerknes V, Duston J, Knox D, Harmon P. Importance of body size for acclimation of underyearling Atlantic salmon parr (Salmo salar L.) to seawater. Aquaculture. 1992; 104(3):357-366. https://doi.org/10.1016/00448486(92)90216-8

6. Handeland SO, Imsland AK, Bjornsson BT, Stefansson SO. Long-term effects of photoperiod, temperature and their interaction on growth, gill $\mathrm{Na}^{+}, \mathrm{K}^{+}$-ATPase activity, seawater tolerance and plasma growth-hormone levels in Atlantic salmon Salmo salar. J Fish Biol. 2013; 83(5):1197-1209. https://doi.org/10.1111/jfb.12215

7. Morgan JD, Iwama GK. Effects of salinity on growth, metabolism, and ion regulation in juvenile rainbow and steelhead trout (Oncorhynchus mykiss) and fall chinook salmon (Oncorhynchus tshawytscha). Can J Fish Aquat Sci. 1991; 48(11):2083-2094. https://doi.org/10.1139/f91-247

8. Huang M, Zhou Y, Liu C, Davis DA, Li L, Gao Q et al. Fatty acid composition, osmolality, $\mathrm{Na}^{+}, \mathrm{K}^{+}$-ATPase activity, cortisol content and antioxidant status of rainbow trout (Oncorhynchus mykiss) in response to various dietary 
levels of eicosapentaenoic acid and docosahexaenoic acid. Aquac Res. 2020(00):1-13.

https://doi.org/10.1111/are.14617

9. Huang M, Zhou Y, Ge J, Agustsson T, Li L, Gao Q et al. Fatty acid composition and digestive enzyme activities of rainbow trout in response to dietary docosahexaenoic acid (DHA) and eicosapentaenoic acid (EPA) during salinity acclimation. J Ocean Univ China. 2020; 19(6):1430-1440. https://doi.org/10.1007/s11802-020-4470-9

10. Handeland S, Berge Å, Björnsson BT, Lie $\emptyset$, Stefansson S. Seawater adaptation by out-of-season Atlantic salmon (Salmo salar L.) smolts at different temperatures. Aquaculture. 2000; 181(3-4):377-396.

https://doi.org/10.1016/S0044-8486(99)00241-0

11. Ge J, Huang M, Zhou Y, Deng Q, Liu R, Gao Q et al. Effects of seawater acclimation at constant and diel cyclic temperatures on growth, osmoregulation and branchial phospholipid fatty acid composition in rainbow trout Oncorhynchus mykiss. J Comp Physiol, B. 2021. https://doi.org/10.1007/s00360-020-01330-0

12. Andersen OS, Koeppe RE. Bilayer thickness and membrane protein function: an energetic perspective. Annu Rev Biophys Biomol Struct. 2007; 36(1):107-130. https://doi.org/10.1146/annurev.biophys.36.040306.132643

13. Ernst R, Ejsing CS, Antonny B. Homeoviscous adaptation and the regulation of membrane lipids. J Mol Biol. 2016; 428(24, Part A):4776-4791. https://doi.org/10.1016/j.jmb.2016.08.013

14. Gennis RB. Biomembranes: molecular structure and function. New York, USA: Springer-Verlag; 1989. https://doi.org/10.1007/978-1-4757-2065-5

15. Liu C, Zhou Y, Dong K, Sun D, Gao Q, Dong S. Differences in fatty acid composition of gill and liver phospholipids between Steelhead trout Oncorhynchus mykiss and Atlantic salmon Salmo salar under declining temperatures. Aquaculture. 2018; 495:815-822. https://doi.org/10.1016/j.aquaculture.2018.06.045

16. Liu C, Ge J, Zhou Y, Thirumurugan R, Gao Q, Dong S. Effects of decreasing temperature on phospholipid fatty acid composition of different tissues and hematology in Atlantic salmon (Salmo salar). Aquaculture. 2020; 515:734587. https://doi.org/10.1016/j.aquaculture.2019.734587

17. Shivkamat $P$, Roy R. Regulation of membrane lipid bilayer structure during salinity adaptation: A study with the gill epithelial cell membranes of Oreochromis niloticus. Comp Biochem Phys B. 2005; 142(1):28-36.

https://doi.org/10.1016/j.cbpc.2005.05.014

18. Kelly AM, Kohler CC. Cold tolerance and fatty acid composition of striped bass, white bass, and their hybrids. $\mathrm{N}$ Am J Aquacult. 1999; 61(4):278-285. https:/doi.org/10.1577/1548-8454(1999)061<0278:ctafac>2.0.c0;2

19. Snyder RJ, Schregel WD, Wei Y. Effects of thermal acclimation on tissue fatty acid composition of freshwater alewives Alosa pseudoharengus. Fish Physiol Biochem. 2012; 38(2):363-373. https://doi.org/10.1007/s10695011-9513-0

20. Fadhlaoui M, Couture P. Combined effects of temperature and metal exposure on the fatty acid composition of cell membranes, antioxidant enzyme activities and lipid peroxidation in yellow perch (Perca flavescens). Aquat Toxicol. 2016; 180:45-55. https://doi.org/10.1016/j.aquatox.2016.09.005

21. Bystriansky JS, Ballantyne JS. Gill $\mathrm{Na}^{+}-\mathrm{K}^{+}$-ATPase activity correlates with basolateral membrane lipid composition in seawater- but not freshwater-acclimated Arctic char (Salvelinus alpinus). Am J Physiol-Reg I. 2007; 292(2):R1043-R1051. https://doi.org/10.1152/ajpregu.00189.2005

22. Han C, Dong S, Li L, Gao Q, Zhou Y. Assessment of phospholipid fatty acid profiles for discrimination of salmonids cultured in freshwater and seawater. Food Control. 2021; 120:107493.

https://doi.org/10.1016/j.foodcont.2020.107493

23. Donaldson MR, Cooke SJ, Patterson DA, Macdonald JS. Cold shock and fish. J Fish Biol. 2008; 73(7):1491-1530. https://doi.org/10.1111/j.1095-8649.2008.02061.x

Page $12 / 24$ 
24. Farkas T, Fodor E, Kitajka K, Halver JE. Response of fish membranes to environmental temperature. Aquac Res. 2001; 32(8):645-655. https://doi.org/10.1046/j.1365-2109.2001.00600.x

25. Hazel JR. Effects of temperature on the structure and metabolism of cell membranes in fish. Am J Physiol-Reg I. 1984; 246(4):R460-R470. https://doi.org/10.1152/ajpregu.1984.246.4.R460

26. Skalli A, Robin JH, Le Bayon N, Le Delliou H, Person-Le Ruyet J. Impact of essential fatty acid deficiency and temperature on tissues' fatty acid composition of European sea bass (Dicentrarchus labrax). Aquaculture. 2006; 255(1):223-232. https://doi.org/10.1016/j.aquaculture.2005.12.006

27. Leray C, Chapelle S, Duportail G, Florentz A. Changes in fluidity and 22:6(n-3) content in phospholipids of trout intestinal brush-border membrane as related to environmental salinity. BBA-Biomembranes. 1984; 778(2):233238. https://doi.org/10.1016/0005-2736(84)90363-8

28. Blicher A, Wodzinska K, Fidorra M, Winterhalter M, Heimburg T. The temperature dependence of lipid membrane permeability, its quantized nature, and the influence of anesthetics. Biophys J. 2009; 96(11):4581-4591. https://doi.org/10.1016/j.bpj.2009.01.062

29. Tocher DR, Bendiksen EÅ, Campbell PJ, Bell JG. The role of phospholipids in nutrition and metabolism of teleost fish. Aquaculture. 2008; 280(1-4):21-34. https://doi.org/10.1016/j.aquaculture.2008.04.034

30. Borlongan IG, Benitez LV. Lipid and fatty acid composition of milkfish (Chanos chanos Forsskal) grown in freshwater and seawater. Aquaculture. 1992; 104(1):79-89. https://doi.org/10.1016/0044-8486(92)90139-C

31. Genz J, Esbaugh AJ, Grosell M. Intestinal transport following transfer to increased salinity in an anadromous fish (Oncorhynchus mykiss). Comp Biochem Phys A. 2011; 159(2):150-158.

https://doi.org/10.1016/j.cbpa.2011.02.011

32. Sundh H, Kvamme BO, Fridell F, Olsen RE, Ellis T, Taranger GL et al. Intestinal barrier function of Atlantic salmon (Salmo salar L.) post smolts is reduced by common sea cage environments and suggested as a possible physiological welfare indicator. BMC Physiol. 2010; 10:22. https://doi.org/10.1186/1472-6793-10-22

33. Brijs J, Hennig GW, Gräns A, Dekens E, Axelsson M, Olsson C. Exposure to seawater increases intestinal motility in euryhaline rainbow trout (Oncorhynchus mykiss). J Exp Biol. 2017; 220(13):2397-2408.

https://doi.org/10.1242/jeb.156000

34. Edwards SL, Marshall WS. 1 - Principles and Patterns of Osmoregulation and Euryhalinity in Fishes. In:Edited by McCormick SD, Farrell AP, Brauner CJ. Fish Physiology. vol. 32: Academic Press; 2012: 1-44.

https://doi.org/10.1016/B978-0-12-396951-4.00001-3

35. Eldridge WH, Sweeney BW, Law JM. Fish growth, physiological stress, and tissue condition in response to rate of temperature change during cool or warm diel thermal cycles. Can J Fish Aquat Sci. 2015; 72(10):1527-1537. https://doi.org/10.1139/cjfas-2014-0350

36. Sims DW, Wearmouth VJ, Southall EJ, Hill JM, Moore P, Rawlinson K et al. Hunt warm, rest cool: bioenergetic strategy underlying diel vertical migration of a benthic shark. J Anim Ecol. 2006; 75(1):176-190. https://doi.org/10.1111/j.1365-2656.2005.01033.x

37. Thomas RE, Gharrett JA, Carls MG, Rice SD, Moles A, Korn S. Effects of fluctuating temperature on mortality, stress, and energy reserves of juvenile coho salmon. Trans Am Fish Soc. 1986; 115(1):52-59. https://doi.org/10.1577/1548-8659(1986)115<52:Eoftom>2.0.Co;2

38. Lushchak VI. Environmentally induced oxidative stress in aquatic animals. Aquat Toxicol. 2011; 101(1):13-30. https://doi.org/10.1016/j.aquatox.2010.10.006

39. Martínez-Álvarez RM, Morales AE, Sanz A. Antioxidant defenses in fish: Biotic and Abiotic Factors. Rev Fish Biol Fisher. 2005; 15(1):75-88. https://doi.org/10.1007/s11160-005-7846-4

Page $13 / 24$ 
40. Tunnah L, Currie S, Maccormack TJ. Do prior diel thermal cycles influence the physiological response of Atlantic salmon (Salmo salar) to subsequent heat stress? Can J Fish Aquat Sci. 2017; 74(1):127-139.

https://doi.org/10.1139/cjfas-2016-0157

41. Hokanson KE, Kleiner CF, Thorslund TW. Effects of constant temperatures and diel temperature fluctuations on specific growth and mortality rates and yield of juvenile rainbow trout, Salmo gairdneri. J Fish Board Can. 1977; 34(5):639-648.

42. McCormick SD. Endocrine control of osmoregulation in teleost fish. Am Zool. 2001; 41(4):781-794. https://doi.org/10.1093/icb/41.4.781

43. Johannsson A, Smith GA, Metcalfe JC. The effect of bilayer thickness on the activity of $\left(\mathrm{Na}^{+}+\mathrm{K}^{+}\right)-\mathrm{ATPase}$. BBABiomembranes. 1981; 641(2):416-421. https://doi.org/10.1016/0005-2736(81)90498-3

44. Vorobyov I, Olson Timothy E, Kim Jung H, Koeppe Roger E, Andersen Olaf S, Allen Toby W. Ion-Induced defect permeation of lipid membranes. Biophys J. 2014; 106(3):586-597. https://doi.org/10.1016/j.bpj.2013.12.027

45. Percie du Sert N, Ahluwalia A, Alam S, Avey MT, Baker M, Browne WJ et al. Reporting animal research: Explanation and elaboration for the ARRIVE guidelines 2.0. PLoS Biol. 2020; 18(7):e3000411.

https://doi.org/10.1371/journal.pbio.3000411

46. Wallaert C, Babin PJ. Thermal adaptation affects the fatty acid composition of plasma phospholipids in trout. Lipids. 1994; 29(5):373-376. https://doi.org/10.1007/bf02537193

47. Snyder RJ, Hennessey TM. Cold tolerance and homeoviscous adaptation in freshwater alewives Alosa pseudoharengus. Fish Physiol Biochem. 2003; 29(2):117-126.

https://doi.org/10.1023/b:Fish.0000035920.60817.11

48. Cornelius F, Turner N, Christensen HRZ. Modulation of Na,K-ATPase by Phospholipids and Cholesterol. II. SteadyState and Presteady-State Kinetics. Biochemistry. 2003; 42(28):8541-8549. https://doi.org/10.1021/bi034532e

\section{Tables}

Table 1 Liver PLFA composition of rainbow trout in different constant temperatures during seawater acclimation. 


\begin{tabular}{|c|c|c|c|c|c|c|c|c|c|}
\hline SP & FW-28 & & & SW-1 & & & SW-14 & & \\
\hline Temperature & $9^{\circ} \mathrm{C}$ & $12.5^{\circ} \mathrm{C}$ & $16^{\circ} \mathrm{C}$ & $9^{\circ} \mathrm{C}$ & $12.5^{\circ} \mathrm{C}$ & $16^{\circ} \mathrm{C}$ & $9^{\circ} \mathrm{C}$ & $12.5^{\circ} \mathrm{C}$ & $16^{\circ} \mathrm{C}$ \\
\hline \multicolumn{10}{|c|}{ Saturated fatty acid } \\
\hline C14:0 & $1.11^{\mathrm{Ab}}$ & $1.11^{\mathrm{A}}$ & $0.82^{\mathrm{B}}$ & $1.38^{\mathrm{Aa}}$ & $0.83^{\mathrm{B}}$ & $0.97^{\mathrm{B}}$ & $1.04^{b}$ & 1.25 & 1.03 \\
\hline C16:0 & $17.09^{\mathrm{Ba}}$ & $17.39^{\mathrm{B}}$ & $18.95^{\mathrm{Aa}}$ & $17.40^{\mathrm{Aa}}$ & $17.55^{\mathrm{A}}$ & $14.80^{\mathrm{Bb}}$ & $15.53^{\mathrm{Bb}}$ & $18.78^{A}$ & $14.56^{\mathrm{Bb}}$ \\
\hline $\mathrm{C} 17: 0$ & 0.44 & 0.42 & 0.41 & 0.37 & 0.35 & 0.60 & 0.57 & 0.52 & 0.49 \\
\hline C18:0 & $9.45^{\mathrm{Ab}}$ & $7.40^{\mathrm{Bb}}$ & $9.30^{\mathrm{A}}$ & $11.29^{A a}$ & $10.24^{\mathrm{Ba}}$ & $9.21^{\mathrm{C}}$ & $9.18^{\mathrm{Ab}}$ & $9.25^{\mathrm{Aa}}$ & $8.65^{\mathrm{B}}$ \\
\hline $\mathrm{C} 20: 0$ & 0.28 & 0.25 & $0.35^{a}$ & 0.20 & 0.19 & $0.24^{\mathrm{ab}}$ & 0.22 & 0.29 & $0.18^{b}$ \\
\hline $\mathrm{C} 22: 0$ & $0.05^{\mathrm{b}}$ & 0.08 & $0.09^{b}$ & $0.18^{\mathrm{Aa}}$ & $0.05^{\mathrm{B}}$ & $0.06^{\mathrm{Bb}}$ & $0.05^{\mathrm{Bb}}$ & $0.08^{\mathrm{B}}$ & $0.23^{\mathrm{Aa}}$ \\
\hline C23:0 & $0.25^{\mathrm{b}}$ & $0.52^{\mathrm{a}}$ & $0.39^{b}$ & $0.63^{a}$ & $0.54^{a}$ & $0.70^{a}$ & $0.05^{\mathrm{Bc}}$ & $0.06^{\mathrm{Bb}}$ & $0.23^{\mathrm{Ab}}$ \\
\hline $\mathrm{C} 24: 0$ & $0.33^{A c}$ & $0.41^{A B}$ & $0.60^{\mathrm{Ab}}$ & $0.65^{\mathrm{Bb}}$ & $0.63^{\mathrm{B}}$ & $1.16^{\mathrm{Aa}}$ & $1.08^{\mathrm{Aa}}$ & $0.51^{\mathrm{B}}$ & $1.15^{\mathrm{Aa}}$ \\
\hline \SFA & $29.00^{\mathrm{Bb}}$ & $27.57^{\mathrm{Cb}}$ & $30.9^{\mathrm{Aa}}$ & $32.11^{\mathrm{Aa}}$ & $30.38^{\mathrm{Ba}}$ & $27.75^{\mathrm{Cb}}$ & $27.72^{\mathrm{Bc}}$ & $30.73^{\mathrm{Aa}}$ & $26.51^{\mathrm{Bb}}$ \\
\hline \multicolumn{10}{|c|}{ Monounsaturated fatty acid } \\
\hline C14:1n5 & 0.73 & $0.60^{\mathrm{b}}$ & $0.55^{\mathrm{b}}$ & 0.54 & $0.62^{b}$ & $1.01^{\mathrm{a}}$ & 1.09 & $1.33^{\mathrm{a}}$ & $1.05^{\mathrm{a}}$ \\
\hline C16:1n7 & $1.07^{C}$ & $2.18^{\mathrm{Aa}}$ & $1.96^{\mathrm{Bb}}$ & 1.21 & $1.71^{\mathrm{b}}$ & $1.35^{\mathrm{c}}$ & $1.24^{\mathrm{B}}$ & $1.86^{\mathrm{Bb}}$ & $3.29 \mathrm{Aa}$ \\
\hline C17:1n7 & 0.25 & 0.20 & 0.14 & $0.13^{b}$ & 0.15 & 0.20 & $0.26^{\mathrm{a}}$ & 0.17 & 0.21 \\
\hline C18:1n9 & $7.23^{C}$ & $11.55^{\mathrm{Aa}}$ & $9.18^{\mathrm{Bb}}$ & $7.33^{\mathrm{B}}$ & $8.51^{\mathrm{ABb}}$ & $9.79^{A b}$ & $7.68^{\mathrm{B}}$ & $7.48^{\mathrm{Bc}}$ & $13.95^{\mathrm{Aa}}$ \\
\hline C20:1n9 & 0.28 & 0.21 & 0.30 & 0.24 & 0.22 & 0.25 & 0.26 & 0.30 & 0.25 \\
\hline C22:1n9 & $0.44^{\mathrm{a}}$ & 0.31 & 0.49 & $0.25^{\mathrm{b}}$ & 0.23 & 0.33 & $0.05^{\mathrm{Bc}}$ & $0.34^{\mathrm{A}}$ & $0.41^{\mathrm{A}}$ \\
\hline C24:1n9 & $3.05^{\mathrm{Aa}}$ & $2.55^{\mathrm{B}}$ & $3.16^{\mathrm{A}}$ & $2.57^{\mathrm{Bb}}$ & $2.44^{\mathrm{B}}$ & $3.24^{\mathrm{A}}$ & $3.39^{A a b}$ & $2.67^{A B}$ & $2.41^{\mathrm{B}}$ \\
\hline 『MUFA & $13.04^{C}$ & $17.59^{A a}$ & $15.78^{\mathrm{Bb}}$ & $12.26^{\mathrm{B}}$ & $13.87^{\mathrm{Bb}}$ & $16.18^{A b}$ & $13.98^{\mathrm{B}}$ & $14.16^{\mathrm{Bb}}$ & $21.57^{\mathrm{Aa}}$ \\
\hline \multicolumn{10}{|c|}{ Polyunsaturated fatty acid } \\
\hline C18:2n6 & $4.57^{\mathrm{Ba}}$ & $5.25^{\mathrm{Aa}}$ & $4.17^{\mathrm{Cb}}$ & $3.61^{\mathrm{b}}$ & $3.43^{c}$ & $4.24^{\mathrm{ab}}$ & $4.58^{a b}$ & $4.56^{b}$ & $5.52^{a}$ \\
\hline C18:3n3 & $2.01^{a}$ & $2.02^{a}$ & 2.07 & $1.71^{\mathrm{Bb}}$ & $1.64^{\mathrm{Bc}}$ & $1.94^{\mathrm{A}}$ & $2.11^{\mathrm{Aa}}$ & $1.87^{\mathrm{Bb}}$ & $2.03^{\mathrm{A}}$ \\
\hline C18:3n6 & 0.23 & 0.19 & 0.21 & 0.17 & 0.11 & 0.14 & 0.18 & 0.15 & 0.14 \\
\hline $\mathrm{C} 20: 2 \mathrm{n} 6$ & $1.85^{\mathrm{Aa}}$ & $1.09^{A B}$ & $0.82^{\mathrm{B}}$ & $0.95^{\mathrm{ABC}}$ & $0.87^{B}$ & $1.44^{\mathrm{A}}$ & $1.52^{\mathrm{b}}$ & 1.35 & 1.51 \\
\hline $\mathrm{C} 20: 3 \mathrm{n} 3$ & $2.07^{A b}$ & $1.26^{\mathrm{Bb}}$ & $1.19^{B}$ & $1.23^{c}$ & $2.04^{a}$ & 1.52 & $2.19^{\mathrm{Aa}}$ & $1.57^{\mathrm{Bb}}$ & $1.24^{\mathrm{C}}$ \\
\hline C20:3n6 & $1.06^{\mathrm{a}}$ & $1.60^{\mathrm{a}}$ & $1.83^{a}$ & $0.66^{b}$ & $0.93^{b}$ & $0.83^{b}$ & $0.62^{\mathrm{Bb}}$ & $1.05^{\mathrm{Ab}}$ & $0.64^{\mathrm{Bb}}$ \\
\hline C20:4n6 & $5.30^{\mathrm{Aa}}$ & $4.26^{\mathrm{Ba}}$ & $2.72^{\mathrm{Cb}}$ & $3.73^{\mathrm{Bc}}$ & $3.59^{\mathrm{Bb}}$ & $4.76^{\mathrm{Aa}}$ & $4.61^{\mathrm{b}}$ & $4.42^{a}$ & $4.02^{a}$ \\
\hline
\end{tabular}




\begin{tabular}{|llllllllll|}
$\mathrm{C} 20: 5 \mathrm{n} 3$ & $4.36^{\mathrm{b}}$ & 4.14 & 4.39 & $5.40^{\mathrm{Aa}}$ & $4.61^{\mathrm{B}}$ & $4.63^{\mathrm{B}}$ & $5.87^{\mathrm{Aa}}$ & $4.71^{\mathrm{B}}$ & $4.98^{\mathrm{B}}$ \\
\hline $\mathrm{C} 22: 2 \mathrm{n} 6$ & $0.20^{\mathrm{b}}$ & $0.17^{\mathrm{b}}$ & $0.11^{\mathrm{b}}$ & $0.08^{\mathrm{Bc}}$ & $0.45^{\mathrm{Aa}}$ & $0.34^{\mathrm{Aa}}$ & $0.30^{\mathrm{Aa}}$ & $0.09^{\mathrm{Cb}}$ & $0.21^{\mathrm{Bab}}$ \\
\hline $\mathrm{C} 22: 6 \mathrm{n} 3$ & $36.31^{\mathrm{Ab}}$ & $34.85^{\mathrm{Cb}}$ & $35.81^{\mathrm{Ba}}$ & $38.09^{\mathrm{Aa}}$ & $38.07^{\mathrm{Aa}}$ & $36.23^{\mathrm{Ba}}$ & $36.31^{\mathrm{Ab}}$ & $35.34^{\mathrm{Ab}}$ & $31.67^{\mathrm{Bb}}$ \\
\hline 『PUFA & $57.96^{\mathrm{Aa}}$ & $54.84^{\mathrm{B}}$ & $53.32^{\mathrm{Cb}}$ & $55.63^{\mathrm{b}}$ & 55.75 & $56.07^{\mathrm{a}}$ & $58.30^{\mathrm{Aa}}$ & $55.11^{\mathrm{B}}$ & $51.92^{\mathrm{Cb}}$ \\
\hline
\end{tabular}

Note: Values are means of 3 replications. Different lowercase letters indicate significant differences $(P<0.05)$ among different treatments at the same time, and different capital letters indicate significant differences at different times at the same treatment. Data containing mean \pm SD are included in Additional file 2. FW-28: end of growth trial. SW-1: one day after salinity reached 30 . SW-4: four days after salinity reached 30 . SW-7: seven days after salinity reached 30. SW-14: fourteen days after salinity reached 30 .

Table 2 Intestinal PLFA composition of rainbow trout in different constant temperatures during seawater acclimation. 


\begin{tabular}{|c|c|c|c|c|c|c|c|c|c|}
\hline SP & FW-28 & & & SW-1 & & & SW-14 & & \\
\hline Temperature & $9^{\circ} \mathrm{C}$ & $12.5^{\circ} \mathrm{C}$ & $16^{\circ} \mathrm{C}$ & $9{ }^{\circ} \mathrm{C}$ & $12.5^{\circ} \mathrm{C}$ & $16^{\circ} \mathrm{C}$ & $9^{\circ} \mathrm{C}$ & $\begin{array}{l}12.5 \\
{ }^{\circ} \mathrm{C}\end{array}$ & $16^{\circ} \mathrm{C}$ \\
\hline \multicolumn{10}{|c|}{ Saturated fatty acid } \\
\hline C14:0 & $2.73^{\mathrm{B}}$ & $2.26^{\mathrm{C}}$ & $3.32^{\mathrm{Aa}}$ & 2.48 & 1.67 & $2.20^{\mathrm{ab}}$ & 2.50 & 2.49 & $1.63^{b}$ \\
\hline C16:0 & 22.31 & 22.06 & $23.99^{a}$ & 22.37 & 21.55 & $23.58^{\mathrm{a}}$ & $21.16^{\mathrm{B}}$ & $23.10^{\mathrm{A}}$ & $21.38^{\mathrm{Bb}}$ \\
\hline C17:0 & $0.78^{\mathrm{B}}$ & $0.49^{\mathrm{Bb}}$ & $1.25^{\mathrm{Aa}}$ & $0.81^{\mathrm{A}}$ & $0.75^{\mathrm{ABa}}$ & $0.58^{\mathrm{Bb}}$ & 0.62 & $0.54^{b}$ & $0.67^{b}$ \\
\hline C18:0 & $10.27^{\mathrm{AB}}$ & $11.51^{\mathrm{A}}$ & $10.22^{\mathrm{Bb}}$ & $9.29^{B}$ & $11.69^{\mathrm{A}}$ & $11.44^{\mathrm{Aab}}$ & 10.45 & 11.23 & $12.57^{a}$ \\
\hline C20:0 & 0.29 & 0.32 & $0.45^{\mathrm{a}}$ & 0.25 & 0.22 & $0.31^{\mathrm{ab}}$ & 0.17 & 0.26 & $0.17^{b}$ \\
\hline C22:0 & $0.18^{\mathrm{A}}$ & $0.10^{\mathrm{Ba}}$ & $0.11^{\mathrm{B}}$ & 0.14 & $0.16^{\mathrm{a}}$ & 0.18 & 0.11 & $0.05^{b}$ & 0.16 \\
\hline C23:0 & $0.12^{\mathrm{AB}}$ & $0.07^{B}$ & $0.13^{\mathrm{A}}$ & $0.13^{\mathrm{A}}$ & $0.04^{\mathrm{B}}$ & $0.11^{\mathrm{A}}$ & 0.12 & 0.07 & 0.11 \\
\hline C24:0 & $1.04^{\mathrm{B}}$ & $0.76^{\mathrm{C}}$ & $2.91^{\mathrm{Aa}}$ & 1.05 & 0.96 & $1.19^{\mathrm{b}}$ & 1.54 & 0.68 & $1.16^{\mathrm{b}}$ \\
\hline$\triangle S F A$ & $37.71^{\mathrm{B}}$ & $37.59^{\mathrm{B}}$ & $42.38^{\mathrm{Aa}}$ & $36.53^{\mathrm{B}}$ & $37.04^{\mathrm{B}}$ & $39.60^{\mathrm{Ab}}$ & 36.66 & 38.42 & $37.84^{c}$ \\
\hline \multicolumn{10}{|c|}{ Monounsaturated fatty acid } \\
\hline C14:1n5 & $1.64^{\mathrm{Ba}}$ & $1.06^{\mathrm{C}}$ & $2.93^{\mathrm{Aa}}$ & $0.86^{\mathrm{Cb}}$ & $1.19^{\mathrm{B}}$ & $1.61^{\mathrm{Ab}}$ & $0.93^{b}$ & 1.05 & $0.62^{c}$ \\
\hline C16:1n7 & 1.86 & 1.51 & 1.51 & $2.40^{\mathrm{A}}$ & $1.26^{\mathrm{B}}$ & $1.39^{\mathrm{B}}$ & $2.13^{\mathrm{A}}$ & $1.72^{\mathrm{AB}}$ & $1.38^{\mathrm{B}}$ \\
\hline $\mathrm{C} 17: 1 \mathrm{n} 7$ & $0.53^{\mathrm{a}}$ & 0.47 & 0.45 & $0.29^{\mathrm{Bb}}$ & $0.45^{\mathrm{A}}$ & $0.19^{B}$ & $0.34^{\mathrm{b}}$ & 0.40 & 0.34 \\
\hline C18:1n9 & $10.85^{\mathrm{a}}$ & $9.39^{a}$ & $10.21^{\mathrm{a}}$ & $8.20^{\mathrm{Bb}}$ & $10.68^{\mathrm{Aa}}$ & $9.47^{\mathrm{ABab}}$ & $8.32^{b}$ & $7.42^{\mathrm{b}}$ & $8.86^{\mathrm{b}}$ \\
\hline C20:1n9 & $0.23^{b}$ & 0.22 & $0.35^{\mathrm{a}}$ & $0.21^{\mathrm{b}}$ & 0.17 & $0.19^{b}$ & $0.35^{\mathrm{a}}$ & 0.23 & $0.27^{\mathrm{ab}}$ \\
\hline C22:1n9 & 0.60 & $0.54^{\mathrm{b}}$ & $0.85^{\mathrm{a}}$ & 0.71 & $0.77^{\mathrm{a}}$ & $0.64^{b}$ & 0.52 & $0.57^{b}$ & $0.52^{b}$ \\
\hline C24:1n9 & 2.49 & $3.22^{\mathrm{a}}$ & $3.24^{\mathrm{a}}$ & 3.01 & $3.49^{\mathrm{a}}$ & $2.53^{\mathrm{ab}}$ & $2.39^{\mathrm{A}}$ & $2.55^{\mathrm{Ab}}$ & $1.63^{\mathrm{Bb}}$ \\
\hline 『MUFA & $18.19^{\mathrm{ABa}}$ & $16.42^{\mathrm{Ba}}$ & $19.54^{\mathrm{Aa}}$ & $15.67^{\mathrm{Bb}}$ & $18.02^{\mathrm{Aa}}$ & $16.01^{\mathrm{Bb}}$ & $14.98^{b}$ & $13.93^{b}$ & $13.62^{c}$ \\
\hline \multicolumn{10}{|c|}{ Polyunsaturated fatty acid } \\
\hline C18:2n6 & $3.83^{\mathrm{Bb}}$ & $5.52^{\mathrm{Aa}}$ & $4.96^{\mathrm{Ab}}$ & $5.07^{a}$ & $4.50^{\mathrm{ab}}$ & $4.19^{b}$ & $3.93^{b}$ & $3.75^{b}$ & $7.01^{\mathrm{a}}$ \\
\hline C18:3n3 & $2.75^{\mathrm{AB}}$ & $2.30^{\mathrm{B}}$ & $3.80^{\mathrm{A}}$ & 2.63 & 2.85 & 3.12 & 2.82 & 3.30 & 2.50 \\
\hline C18.3n6 & $0.34^{\mathrm{a}}$ & 0.22 & 0.43 & $0.15^{\mathrm{b}}$ & 0.16 & 0.18 & $0.12^{b}$ & 0.15 & 0.24 \\
\hline C20:2n6 & 0.79 & $0.70^{\mathrm{a}}$ & 0.78 & 0.67 & $0.72^{\mathrm{a}}$ & 0.72 & 0.79 & $0.56^{b}$ & 0.74 \\
\hline C20:3n3 & 1.01 & 1.11 & 0.97 & $0.75^{\mathrm{B}}$ & $1.36^{\mathrm{A}}$ & $0.82^{\mathrm{B}}$ & 1.17 & 1.05 & 0.70 \\
\hline C20:3n6 & 0.55 & 0.67 & $0.73^{\mathrm{a}}$ & $0.56^{\mathrm{A}}$ & $0.47^{\mathrm{A}}$ & $0.31^{\mathrm{Bb}}$ & 0.45 & 0.64 & $0.53^{\mathrm{a}}$ \\
\hline C20:4n6 & 2.49 & 2.45 & 2.61 & 3.04 & 2.60 & 2.30 & 2.94 & 2.77 & 2.29 \\
\hline
\end{tabular}




\begin{tabular}{|llllllllll|}
\hline C20:5n3 & $1.76^{\mathrm{Bb}}$ & $2.94^{\mathrm{Aa}}$ & $2.17^{\mathrm{AB}}$ & $2.90^{\mathrm{ab}}$ & $2.39^{\mathrm{b}}$ & 2.81 & $3.70^{\mathrm{a}}$ & $3.70^{\mathrm{a}}$ & 2.74 \\
\hline $\mathrm{C} 22: 2 \mathrm{n} 6$ & $0.33^{\mathrm{a}}$ & $0.18^{\mathrm{b}}$ & $0.38^{\mathrm{a}}$ & $0.15^{\mathrm{Bb}}$ & $0.31^{\mathrm{Aa}}$ & $0.25^{\mathrm{Aab}}$ & $0.16^{\mathrm{b}}$ & $0.23^{\mathrm{ab}}$ & $0.19^{\mathrm{b}}$ \\
\hline C22:6n3 & $30.24^{\mathrm{Ab}}$ & $29.90^{\mathrm{A}}$ & $21.25^{\mathrm{Bb}}$ & $31.89^{\mathrm{ab}}$ & 29.58 & $29.71^{\mathrm{a}}$ & $32.28^{\mathrm{a}}$ & 31.50 & $31.61^{\mathrm{a}}$ \\
\hline QPUFA & $44.09^{\mathrm{Ab}}$ & $45.99^{\mathrm{Aab}}$ & $38.07^{\mathrm{BC}}$ & $47.80^{\mathrm{Aa}}$ & $44.94^{\mathrm{Bb}}$ & $44.39^{\mathrm{Bb}}$ & $48.35^{\mathrm{a}}$ & $47.65^{\mathrm{a}}$ & $48.54^{\mathrm{a}}$ \\
\hline
\end{tabular}

Note: Same as Table 1.

Table 3 Liver PLFA composition (\%) in rainbow trout at different sampling points at diel cyclic temperatures. 


\begin{tabular}{|c|c|c|c|c|c|c|c|c|c|}
\hline SP & FW-42 & & & SW-1 & & & SW-21 & & \\
\hline Temp & CT & VT2 & VT4 & $\mathrm{CT}$ & VT2 & VT4 & CT & VT2 & VT4 \\
\hline \multicolumn{10}{|c|}{ Saturated fatty acid } \\
\hline C14:0 & $0.96^{\mathrm{b}}$ & $1.00^{\mathrm{b}}$ & $0.97^{b}$ & $1.18^{\mathrm{a}}$ & $1.16^{\mathrm{a}}$ & $1.13^{a}$ & $1.07^{\mathrm{ab}}$ & $1.19^{a}$ & $1.11^{\mathrm{a}}$ \\
\hline C16:0 & $17.26^{\mathrm{AB}}$ & $15.98^{\mathrm{Bc}}$ & $17.90^{\mathrm{Aa}}$ & 16.95 & $17.40^{\mathrm{b}}$ & $16.50^{\mathrm{b}}$ & 18.41 & $18.77^{a}$ & $18.26^{\mathrm{a}}$ \\
\hline $\mathrm{C} 17: 0$ & $0.61^{a b}$ & 0.53 & $0.71^{a}$ & $0.44^{\mathrm{ABb}}$ & $0.57^{\mathrm{A}}$ & $0.26^{\mathrm{Bb}}$ & $0.74^{a}$ & 0.61 & $0.67^{a}$ \\
\hline C18:0 & $6.23^{b}$ & $6.21^{b}$ & $6.27^{c}$ & $7.66^{\mathrm{a}}$ & $7.63^{\mathrm{a}}$ & $7.35^{\mathrm{b}}$ & $8.09^{a}$ & $7.70^{a}$ & $8.20^{a}$ \\
\hline C20:0 & 0.21 & $0.19^{a}$ & 0.19 & 0.13 & $0.13^{a b}$ & 0.14 & 0.15 & $0.09^{b}$ & 0.15 \\
\hline $\mathrm{C} 22: 0$ & 0.12 & 0.09 & 0.16 & 0.08 & 0.12 & 0.08 & 0.10 & 0.09 & 0.08 \\
\hline C24:0 & $0.52^{\mathrm{Bb}}$ & $0.94^{\mathrm{A}}$ & $0.79^{A B a}$ & $0.76^{a}$ & 0.82 & $0.38^{b}$ & $0.63^{\mathrm{Aab}}$ & $0.42^{B}$ & $0.48^{\mathrm{ABb}}$ \\
\hline$\triangle S F A$ & $25.92^{b}$ & $24.94^{b}$ & $27.00^{b}$ & $27.20^{a b}$ & $27.82^{a}$ & $25.84^{b}$ & $29.19^{a}$ & $28.87^{a}$ & $28.96^{a}$ \\
\hline \multicolumn{10}{|c|}{ Monounsaturated fatty acid } \\
\hline C14:1n5 & $0.79^{b}$ & 0.78 & $0.98^{b}$ & $0.60^{b}$ & 0.92 & $0.59^{c}$ & $1.42^{a}$ & 1.01 & $1.28^{a}$ \\
\hline C16:1n7 & $2.61^{a}$ & $2.54^{\mathrm{a}}$ & $2.70^{a}$ & $1.42^{b}$ & $2.04^{\mathrm{ab}}$ & $2.14^{\mathrm{ab}}$ & $1.23^{b}$ & $1.34^{b}$ & $1.59^{b}$ \\
\hline C17:1n7 & 0.23 & 0.19 & 0.20 & $0.23^{A}$ & $0.20^{\mathrm{A}}$ & $0.17^{\mathrm{B}}$ & 0.19 & 0.22 & 0.21 \\
\hline C18:1n9 & $2.01^{a}$ & $2.09^{a}$ & $2.11^{\mathrm{a}}$ & $1.51^{\mathrm{Bb}}$ & $1.68^{A B b}$ & $1.86^{\mathrm{Aa}}$ & $1.60^{b}$ & $1.55^{\mathrm{b}}$ & $1.56^{b}$ \\
\hline C20:1n9 & 0.20 & 0.17 & 0.15 & 0.18 & 0.16 & 0.20 & 0.18 & 0.13 & 0.17 \\
\hline C22:1n9 & 0.08 & 0.05 & 0.08 & 0.06 & 0.05 & 0.05 & 0.06 & 0.06 & 0.04 \\
\hline C24:1n9 & 2.81 & 2.91 & $2.62^{b}$ & 2.88 & 2.75 & $2.71^{b}$ & 3.18 & 3.01 & $3.19^{a}$ \\
\hline \MUFA & $8.72^{a}$ & $8.72^{a}$ & $8.84^{a}$ & $6.88^{\mathrm{Bb}}$ & $7.80^{A b}$ & $7.72^{A b}$ & $7.88^{a}$ & $7.32^{b}$ & $8.04^{b}$ \\
\hline \multicolumn{10}{|c|}{ Polyunsaturated fatty acid } \\
\hline C18:2n6 & $12.89^{a}$ & $12.86^{a}$ & $12.92^{a}$ & $10.22^{\mathrm{Bb}}$ & $12.00^{\mathrm{Aa}}$ & $13.23^{\mathrm{Aa}}$ & $9.18^{b}$ & $8.89^{b}$ & $9.58^{b}$ \\
\hline C18:3n3 & 0.10 & 0.10 & $0.10^{a b}$ & $0.15^{\mathrm{A}}$ & $0.10^{\mathrm{B}}$ & $0.08^{\mathrm{Bb}}$ & 0.14 & 0.14 & $0.13^{a}$ \\
\hline C18:3n6 & 0.16 & 0.16 & 0.13 & 0.13 & 0.14 & 0.15 & 0.15 & 0.13 & 0.10 \\
\hline C20:2n6 & $1.26^{\mathrm{Aba}}$ & $1.48^{\mathrm{Aa}}$ & $1.12^{\mathrm{B}}$ & $1.18^{a}$ & $1.21^{\mathrm{ab}}$ & 1.36 & $0.79^{b}$ & $0.97^{b}$ & 1.18 \\
\hline C20:3n3 & $0.91^{b}$ & $0.84^{b}$ & $0.84^{b}$ & $1.33^{\mathrm{Aa}}$ & $0.96^{\mathrm{Bb}}$ & $0.94^{\mathrm{Bb}}$ & $1.24^{\mathrm{a}}$ & $1.28^{a}$ & $1.21^{a}$ \\
\hline C20:3n6 & $1.93^{\mathrm{A}}$ & $1.50^{\mathrm{Bab}}$ & $1.29^{\mathrm{Bb}}$ & 2.03 & $1.83^{\mathrm{a}}$ & $2.06^{a}$ & $1.82^{\mathrm{A}}$ & $1.14^{\mathrm{Bb}}$ & $1.54^{\mathrm{ABb}}$ \\
\hline C20:4n6 & $2.92^{\mathrm{Ab}}$ & $2.78^{\mathrm{Ac}}$ & $1.85^{\mathrm{Bc}}$ & $3.37^{b}$ & $3.53^{b}$ & $3.06^{b}$ & $5.19^{a}$ & $4.93^{a}$ & $4.63^{a}$ \\
\hline C20:5n3 & $2.69^{b}$ & 2.52 & $2.12^{b}$ & $3.01^{\mathrm{ab}}$ & 2.90 & $2.80^{a}$ & $3.64^{\mathrm{Aa}}$ & $2.60^{\mathrm{B}}$ & $2.92^{\mathrm{Ba}}$ \\
\hline C22:2n6 & 0.34 & 0.33 & 0.38 & 0.23 & 0.37 & 0.28 & 0.23 & 0.29 & 0.30 \\
\hline
\end{tabular}




\begin{tabular}{|llllllllll|}
\hline C22:6n3 & $42.16^{\mathrm{b}}$ & $43.78^{\mathrm{a}}$ & $43.4^{\mathrm{a}}$ & $44.29^{\mathrm{Aa}}$ & $41.33^{\mathrm{Cb}}$ & $42.47^{\mathrm{Bab}}$ & $40.54^{\mathrm{Bb}}$ & $43.45^{\mathrm{Aa}}$ & $41.39^{\mathrm{Bb}}$ \\
\hline \PUFA & 65.36 & $66.34^{\mathrm{a}}$ & $64.16^{\mathrm{b}}$ & 65.92 & $64.38^{\mathrm{ab}}$ & $66.44^{\mathrm{a}}$ & 62.93 & $63.81^{\mathrm{b}}$ & $63.00^{\mathrm{b}}$ \\
\hline
\end{tabular}

Note: Values represent the mean of 4 replicates. Different lowercase letters indicate significant differences $(P<0.05)$ among different treatments at the same time, and different capital letters indicate significant differences at different times at the same treatment. Data containing mean \pm SD are included in Additional file 2. FW-42: end of growth trial. SW-1: one day after salinity reached 30. SW-21: 21 days after salinity reached 30. SFA: saturated fatty acid, MUFA: monounsaturated fatty acid, PUFA: polyunsaturated fatty acid.

Table 4 Intestinal PLFA composition (\%) in rainbow trout at different sampling points at diel cyclic temperatures. 


\begin{tabular}{|c|c|c|c|c|c|c|c|c|c|}
\hline SP & FW-42 & & & SW-1 & & & SW-21 & & \\
\hline Temp & CT & VT2 & VT4 & CT & VT2 & VT4 & CT & VT2 & VT4 \\
\hline \multicolumn{10}{|c|}{ Saturated fatty acid } \\
\hline C14:0 & $1.27^{\mathrm{b}}$ & $1.14^{\mathrm{b}}$ & $1.02^{\mathrm{c}}$ & $1.28^{\mathrm{b}}$ & $1.20^{\mathrm{b}}$ & $1.25^{\mathrm{b}}$ & $1.50^{\mathrm{a}}$ & $1.72^{\mathrm{a}}$ & $1.67^{a}$ \\
\hline C16:0 & $19.84^{\mathrm{ABa}}$ & $21.32^{\mathrm{A}}$ & $18.76^{\mathrm{B}}$ & $16.96^{\mathrm{Bb}}$ & $20.7^{A}$ & $20.46^{\mathrm{A}}$ & $20.95^{a}$ & 21.37 & 20.20 \\
\hline C17:0 & 0.62 & 0.73 & 0.63 & 0.82 & 0.68 & 1.01 & 0.88 & 1.11 & 0.85 \\
\hline C18:0 & $11.07^{\mathrm{Aa}}$ & $10.36^{\mathrm{A}}$ & $8.69^{\mathrm{BC}}$ & $9.19^{\mathrm{Bb}}$ & $10.41^{\mathrm{B}}$ & $12.59^{\mathrm{Aa}}$ & $10.67^{a}$ & 9.81 & $10.49^{b}$ \\
\hline C20:0 & 0.27 & $0.38^{a}$ & $0.33^{a}$ & $0.26^{\mathrm{AB}}$ & $0.29^{A a b}$ & $0.21^{\mathrm{Bb}}$ & 0.22 & $0.23^{b}$ & $0.22^{b}$ \\
\hline C22:0 & 0.11 & 0.14 & 0.13 & 0.15 & 0.10 & 0.14 & 0.11 & 0.19 & 0.12 \\
\hline $\mathrm{C} 24: 0$ & $0.77^{\mathrm{B}}$ & $1.20^{\mathrm{Aa}}$ & $0.81^{\mathrm{B}}$ & $0.60^{\mathrm{B}}$ & $0.81^{A b}$ & $0.86^{\mathrm{A}}$ & 0.74 & $0.90^{\mathrm{ab}}$ & 0.77 \\
\hline QSFA & $33.94^{\mathrm{Aa}}$ & $35.28^{A}$ & $30.37^{\mathrm{Bb}}$ & $29.26^{\mathrm{Bb}}$ & $34.19^{A}$ & $36.51^{\mathrm{Aa}}$ & $35.08^{a}$ & 35.32 & $34.31^{a}$ \\
\hline \multicolumn{10}{|c|}{ Monounsaturated fatty acid } \\
\hline C14:1n5 & $0.55^{c}$ & $0.74^{\mathrm{c}}$ & $0.69^{b}$ & $1.00^{b}$ & $1.00^{b}$ & $1.41^{\mathrm{a}}$ & $1.37^{\mathrm{a}}$ & $1.28^{a}$ & $1.28^{\mathrm{a}}$ \\
\hline C16:1n7 & $1.12^{\mathrm{b}}$ & $0.96^{\mathrm{b}}$ & $0.96^{\mathrm{b}}$ & $1.30^{\mathrm{b}}$ & $0.90^{\mathrm{b}}$ & $1.40^{\mathrm{b}}$ & $2.22^{a}$ & $2.78^{a}$ & $2.97^{a}$ \\
\hline C17:1n7 & 0.34 & 0.30 & $0.26^{b}$ & $0.45^{A B}$ & $0.25^{\mathrm{B}}$ & $0.59^{\mathrm{Aa}}$ & 0.34 & 0.40 & $0.37^{b}$ \\
\hline C18:1n9 & 2.07 & $2.22^{b}$ & $1.87^{b}$ & $2.08^{\mathrm{B}}$ & $1.89^{\mathrm{Bc}}$ & $2.57^{\mathrm{Aa}}$ & $2.25^{\mathrm{B}}$ & $2.63^{\mathrm{Aa}}$ & $2.70^{\mathrm{Aa}}$ \\
\hline C20:1n9 & 0.28 & 0.33 & 0.28 & 0.26 & 0.26 & 0.33 & 0.27 & 0.33 & 0.31 \\
\hline $\mathrm{C} 22: 1 \mathrm{n} 9$ & 0.07 & 0.10 & 0.08 & 0.07 & 0.09 & 0.08 & 0.10 & 0.09 & 0.10 \\
\hline C24:1n9 & 2.64 & $2.54^{\mathrm{a}}$ & $2.34^{\mathrm{ab}}$ & 2.18 & $2.06^{\mathrm{b}}$ & $2.69^{a}$ & $2.36^{\mathrm{A}}$ & $1.95^{\mathrm{Bb}}$ & $1.73^{\mathrm{Bb}}$ \\
\hline \MUFA & $7.07^{b}$ & $7.20^{b}$ & $6.46^{b}$ & $7.32^{\mathrm{Bb}}$ & $6.46^{\mathrm{Bb}}$ & $9.07^{\mathrm{Aa}}$ & $8.90^{a}$ & $9.47^{a}$ & $9.46^{\mathrm{a}}$ \\
\hline \multicolumn{10}{|c|}{ Polyunsaturated fatty acid } \\
\hline C18:2n6 & $10.58^{\mathrm{A}}$ & $9.43^{\mathrm{Ab}}$ & $7.43^{\mathrm{Bb}}$ & $11.7^{\mathrm{B}}$ & $7.06^{\mathrm{Cc}}$ & $13.56^{\mathrm{Aa}}$ & $11.90^{C}$ & $13.35^{\mathrm{Ba}}$ & $14.86^{\mathrm{Aa}}$ \\
\hline C18:3n3 & 0.12 & 0.11 & $0.11^{b}$ & 0.1 & 0.09 & $0.11^{b}$ & 0.09 & 0.15 & $0.20^{a}$ \\
\hline C18:3n6 & $0.16^{b}$ & $0.16^{b}$ & $0.15^{\mathrm{b}}$ & $0.26^{\mathrm{ab}}$ & $0.13^{b}$ & $0.19^{b}$ & $0.36^{a}$ & $0.58^{a}$ & $0.67^{a}$ \\
\hline C20:2n6 & $0.80^{\mathrm{A}}$ & $0.51^{\mathrm{Bb}}$ & $0.59^{A B b}$ & 0.61 & $0.55^{b}$ & $0.76^{a}$ & 0.71 & $0.81^{a}$ & $0.82^{a}$ \\
\hline C20:3n3 & 0.79 & $0.74^{b}$ & 0.69 & 0.73 & $0.69^{b}$ & 0.88 & 0.93 & $0.98^{a}$ & 0.96 \\
\hline C20:3n6 & $1.32^{\mathrm{Aa}}$ & $0.89^{B}$ & $0.91^{\mathrm{B}}$ & $0.89^{b}$ & 0.84 & 1.00 & $0.91^{b}$ & 0.90 & 0.96 \\
\hline C20:4n6 & $3.28^{a}$ & 3.20 & 3.02 & $2.68^{b}$ & 3.11 & 2.86 & $2.99^{a b}$ & 2.72 & 2.76 \\
\hline C20:5n3 & $2.36^{b}$ & $2.06^{b}$ & $2.13^{b}$ & $2.34^{\mathrm{b}}$ & $2.14^{\mathrm{b}}$ & $2.45^{\mathrm{b}}$ & $3.03^{a}$ & $3.19^{a}$ & $3.24^{\mathrm{a}}$ \\
\hline $\mathrm{C} 22: 2 \mathrm{n} 6$ & 0.37 & 0.42 & 0.43 & 0.40 & 0.46 & 0.42 & 0.38 & 0.51 & 0.49 \\
\hline
\end{tabular}




$\begin{array}{llllllllll}\text { C22:6n3 } & 39.21^{\mathrm{Bb}} & 40.01^{\mathrm{Bb}} & 47.71^{\mathrm{Aa}} & 43.71^{\mathrm{Aa}} & 44.27^{\mathrm{Aa}} & 32.16^{\mathrm{Bb}} & 34.71^{\mathrm{Ac}} & 32.02^{\mathrm{Bc}} & 31.28^{\mathrm{Bb}} \\ \text { 『PUFA } & 58.99^{\mathrm{Bb}} & 57.52^{\mathrm{Bb}} & 63.17^{\mathrm{Aa}} & 63.42^{\mathrm{Aa}} & 59.34^{\mathrm{Ba}} & 54.42^{\mathrm{Bb}} & 56.02^{\mathrm{C}} & 55.21^{\mathrm{C}} & 56.23^{\mathrm{b}}\end{array}$

Note: Same as Table 3.

\section{Figures}

Liver PLFA composition

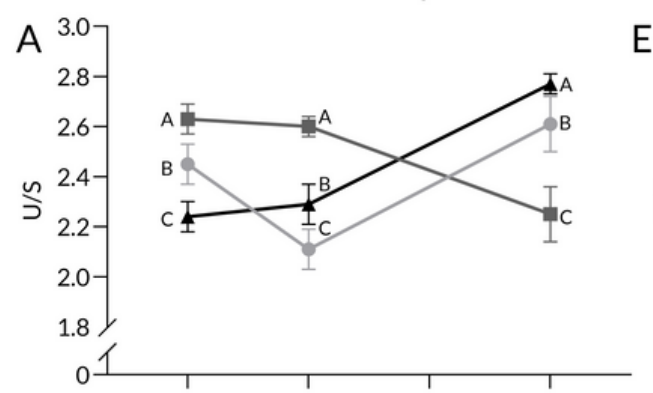

B

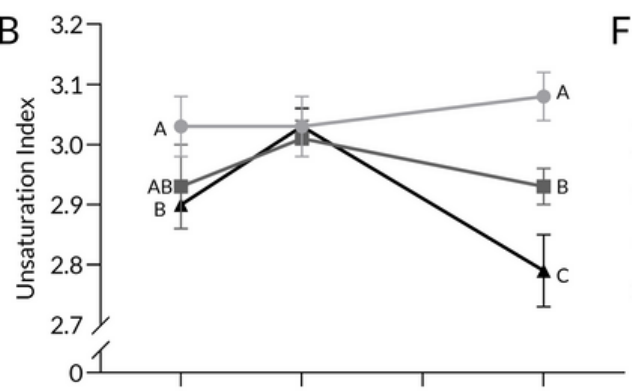

C

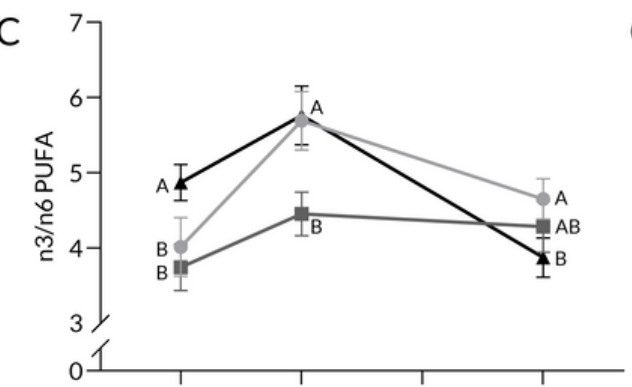

D

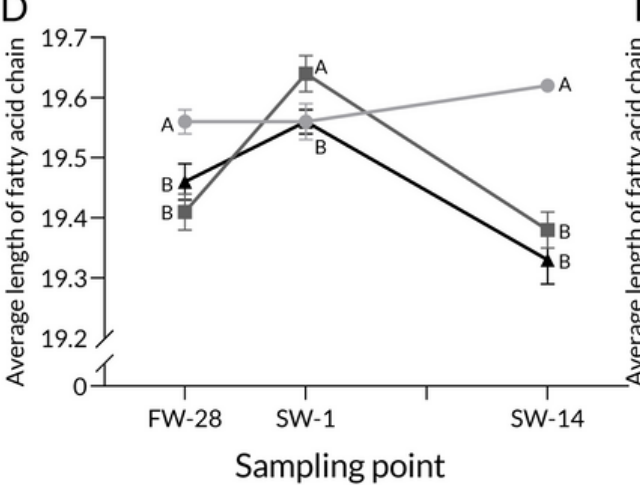

Intestine PLFA composition
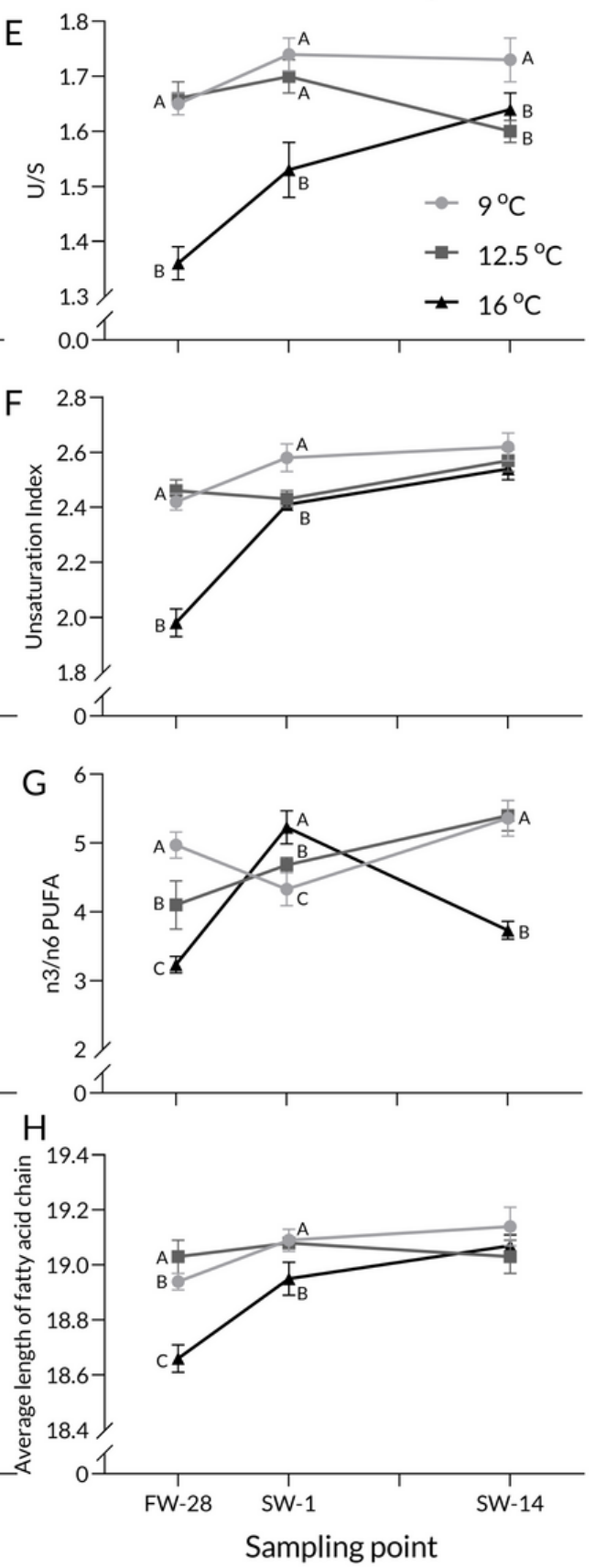

Figure 1 
Liver and intestinal PLFA compositions at different constant temperatures during seawater acclimation of rainbow trout. The ratio of unsaturation (A\&E), unsaturation index (B\&F), the ratio of n-3 PUFA to $n-6$ PUFA (C\&G) and the average length of fatty acid chain $(\mathrm{D} \& \mathrm{H})$. Values are the means of 3 replicates. Capital letters indicate intergroup differences at the same sampling point.
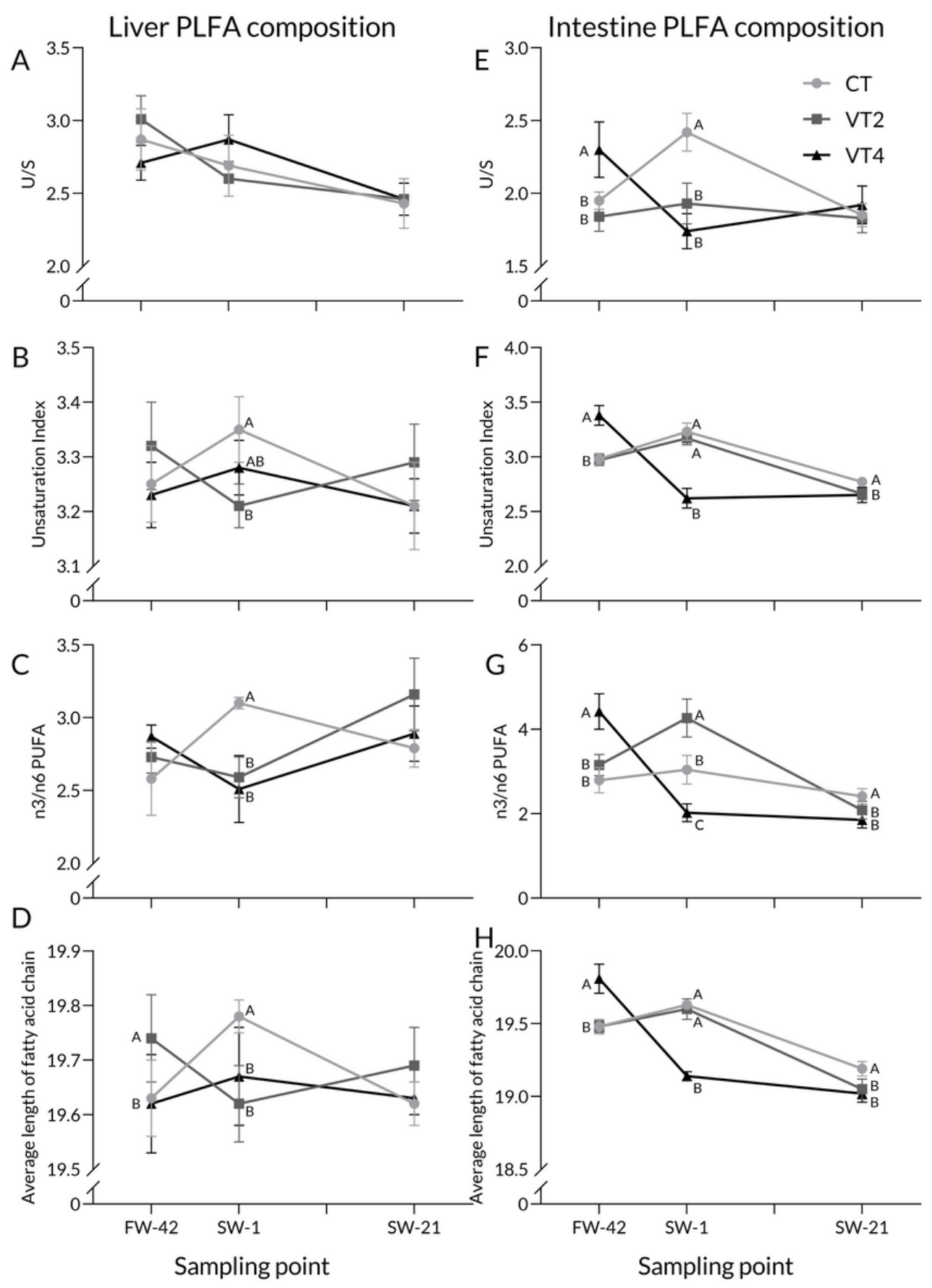

\section{Figure 2}

Liver and intestinal PLFA compositions at diel cyclic temperatures during seawater acclimation in rainbow trout. The ratio of unsaturation (A\&E), unsaturation index (B\&F), the ratio of n-3 PUFA to n-6 PUFA (C\&G) and the average length of fatty acid chain $(D \& H)$. Values are the means of four replicates. Capital letters indicate intergroup differences at the same sampling point. Values are the means of four replicates. Capital letters indicate intergroup differences at the same sampling point. 
Trial 1 - Liver

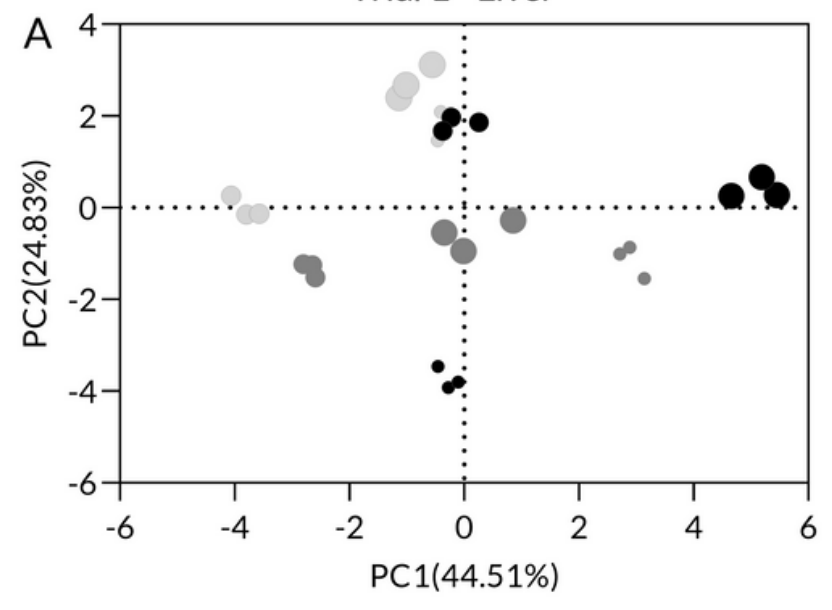

Trial 2 - Liver

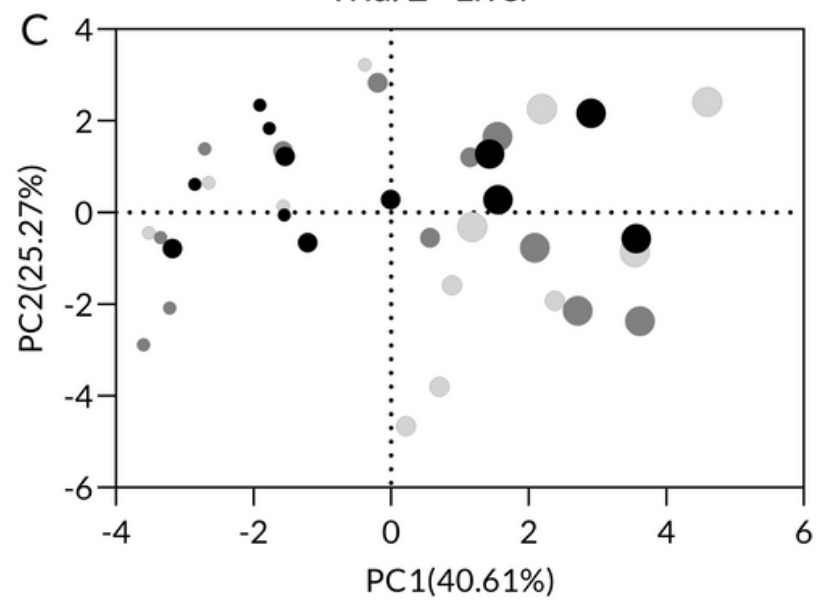

Trial 1 - Intestine

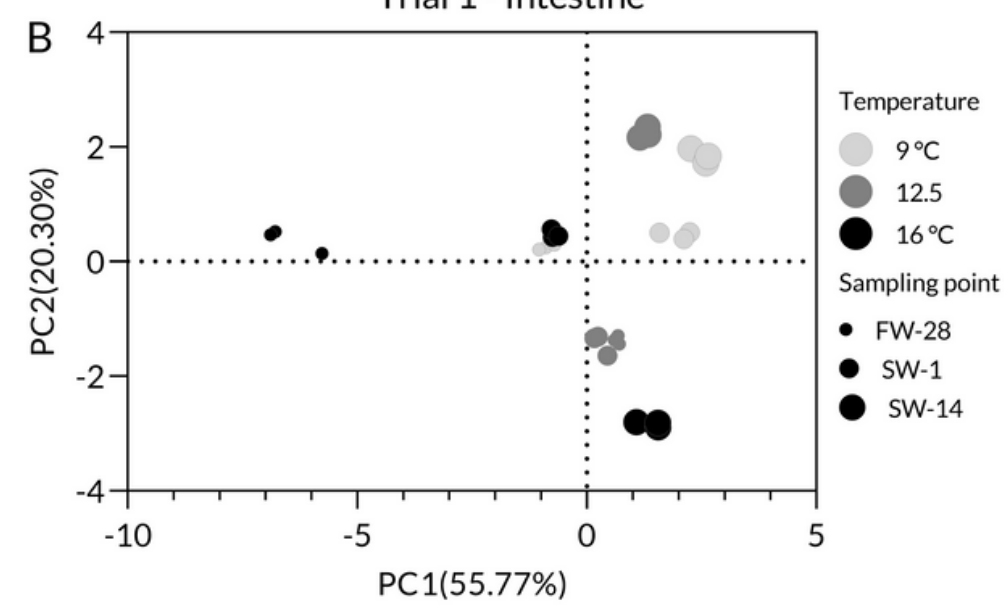

Trial 2 - Intestine

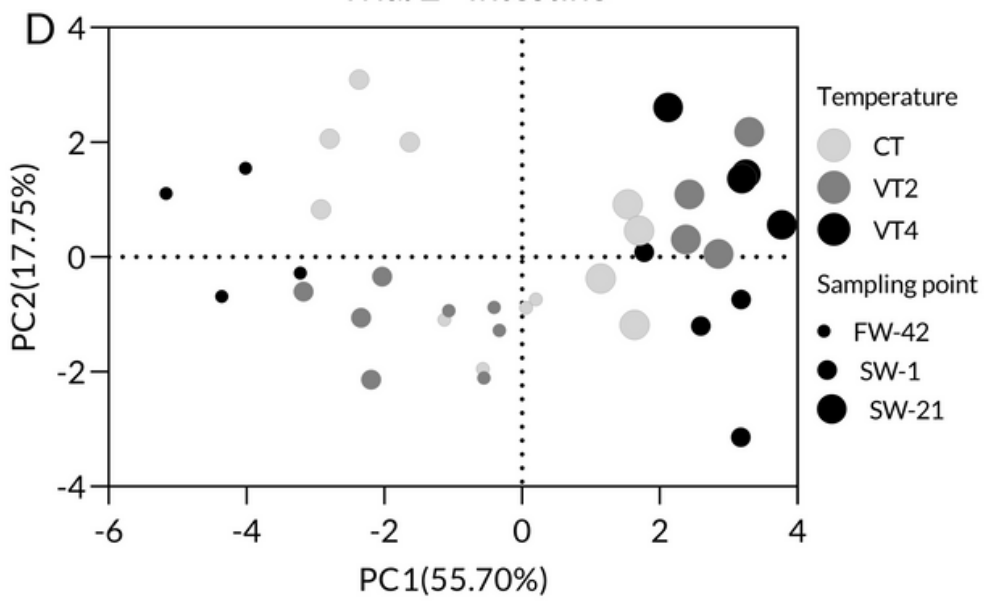

Figure 3

Score plots of liver and intestinal PLFA composition using PCA analysis. Liver (A) and intestine (B) of rainbow trout at different constant temperatures, and liver (C) and intestine (D) of rainbow trout at diel cyclic temperature regimes, using principal component analysis.

\section{Supplementary Files}

This is a list of supplementary files associated with this preprint. Click to download.

- Additionalfile1.docx

- Additionalfile2.docx

- Additionalfile3.docx 